UNIVERSIDADE DE SÃO PAULO

FACULDADE DE MEDICINA DE RIBEIRÃO PRETO

Sérgio Henrique Pires Okano

CARACTERÍSTICAS CLÍNICAS E SOCIODEMOGRÁFICAS DE UMA POPULAÇÃO COM DISFORIA/INCONGRUÊNCIA DE GÊNERO

Ribeirão Preto 
Sérgio Henrique Pires Okano

\section{CARACTERÍSTICAS CLÍNICAS E SOCIODEMOGRÁFICAS DE UMA POPULAÇÃO COM DISFORIA/INCONGRUÊNCIA DE GÊNERO}

\section{VERSÃO ORIGINAL}

Dissertação de Mestrado apresentada a Faculdade de Medicina de Ribeirão Preto da Universidade de São Paulo para obtenção do título de Mestre em Ciências. Aréa de Concentração: Ginecologia e Obstetrícia

Orientadora: Profa. Dra. Lúcia Alves da Silva Lara 
Autorizo a reprodução e divulgação total ou parcial deste trabalho, por qualquer meio convencional ou eletrônico, para fins de estudo e pesquisa, desde que citada a fonte.

Okano, Sérgio Henrique Pires

Características Clínicas e Sociodemográficas de uma População com Disforia/Incongruência de Gênero. Ribeirão Preto, 2020. 87 p. il.

Dissertação de Mestrado, apresentada à Faculdade de Medicina de Ribeirão Preto/USP. Departamento de Ginecologia e Obstetrícia.

Orientadora: Lara, Lúcia Alves da Silva

1. Transexualismo; 2. Pessoas transgêneras; 3. Disforia de gênero; 4. Minorias sexuais e de gênero 
Nome: OKANO, Sergio Henrique Pires

Título: CARACTERÍSTICAS CLÍNICAS E SOCIODEMOGRÁFICAS DE UMA POPULAÇÃO COM DISFORIA/INCONGRUÊNCIA DE GÊNERO

Dissertação de Mestrado apresentada a Faculdade de Medicina de Ribeirão Preto da Universidade de São Paulo para obtenção do título de Mestre em Ciências.

Aréa de Concentração: Ginecologia e Obstetrícia

Aprovado em:

\section{Banca Examinadora}

Prof (a). Dr (a).:

Instituição:

Julgamento: Assinatura:

Prof (a). Dr (a).:

Instituição:

Julgamento: Assinatura:

Prof (a). Dr (a).:

Instituição:

Julgamento: Assinatura: 
"Alguns homens veem as coisas como são, e dizem 'Por quê?' Eu sonho com as coisas que nunca foram e digo 'Por que não? (George Bernard Shaw) 


\section{DEDICÁTORIA E AGRADECIMENTOS}

Aos meus amigos, aos familiares e a todos que estiveram envolvidos de alguma forma no desenvolvimento desta dissertação.

Aos professores. À Dra. Lúcia Alves da Silva Lara, cuja dedicação ao estudo da Sexualidade Humana me tornou um apaixonado pelo tema, e por seu empenho em me trilhar nos caminhos da minha formação pessoal, não só como mestrando, mas como um especialista nesta área de atuação da Sexologia. Ao prof. Omero Benedicto Poli Neto e a prof. Giordana Campos Braga pela clarividência diante dos desafios da estatística e da metodologia científica, tão essenciais a minha formação.

À minha família, por apoiar minhas decisões e por estarem ao meu lado nos momentos de alegria e nos momentos de desespero. Aos meus pais, Sérgio e Cristina, por todo carinho e dedicação durante a trajetória da vida; ao meu irmão, Guilherme, pelo incentivo e companheirismo; à minha família de ribeirão, Sarah e Gabriele, e à Thais, ombro direito de sofrimento conjunto nesta trajetória, e ao meu querido Matheus pela paciência e cumplicidade durante esse trabalho.

Aos amigos, que são muitos e seria desonroso citá-los e, por ventura, me esquecer de alguém.

E, finalmente, o presente trabalho foi realizado com apoio da Coordenação de Aperfeiçoamento de Pessoal de Nível Superior - Brasil (CAPES) por meio do Programa de Excelência Acadêmica (PROEX). 


\section{RESUMO}

OKANO, Sergio Henrique Pires Okano. Características clínicas e sociodemográficas de uma população com disforia/incongruência de gênero. 2020. 87 f. Dissertação (Mestrado em Ciências - Faculdade de Medicina de Ribeirão Preto, Universidade de São Paulo, Ribeirão Preto, 2020.

Introdução: A Disforia/Incongruência de gênero (D/IG) é uma condição em que a identidade de gênero de uma pessoa é incongruente com o sexo biológico designado ao nascimento. A D/IG é uma condição que demanda assistência multiprofissional em saúde para tornar o corpo da pessoa congruente com sua identidade. Objetivos: Identificar o momento de vida em que houve a percepção da $\mathrm{D} / \mathrm{IG}$, descrever as características clínicas e sociodemográficas dessa população e os resultados das avalições hormonais dessas pessoas durante o seguimento no AING. Metodologias: Estudo transversal de revisão de prontuários das pessoas com diagnóstico de D/IG em seguimento no AING de janeiro de 2010 a julho de 2018. Resultados: 125 mulheres trans e 68 homens trans foram avaliados. A percepção da incongruência de gênero foi percebida pela maioria das pessoas com D/IG na infância, porém foi estatisticamente maior em homens trans $(O R: 2.05, p=0,02)$. Cento e vinte e oito referiram exercer atividade remunerada. Homens trans informaram ser estudantes em maior número do que as mulheres trans $(O R=2,15, p=0,03)$. A prostituição foi relatada apenas em mulheres trans, assim como a prevalência de ISTs e HIV. Prevalência de tabagismo, etilismo e drogadição foram respectivamente $35,9 \%, 18,1 \%$ e $11,9 \%$ para todas as pessoas com D/IG; 21,6\%, 17,6\% e 13,6\% para as mulheres trans e 33,8\%, $19,1 \%$ e $11,7 \%$ para os homens trans. E, por fim, a automedicação prévia ao caso novo foi mais frequente nas mulheres trans $(O R: 4,87, p<0,01)$. Em homens trans submetidos ao tratamento com androgênios houve aumento tantos dos níveis de estrogênio quanto de testosterona após início do tratamento, em mulheres trans foi observada a redução da testosterona com a hormônioterapia. Foi observado um nível superior ao esperado para a população feminina nos níveis séricos de testosterona pré-tratamento de homens trans. Conclusão: A percepção da transexualidade ocorre na infância e é mais percebida pelos homens trans. As mulheres trans possuem maior prevalência de HIV, ISTs, casos de prostituição, tabagismo, etilismo e drogadição. Os homens trans frequentam mais escolas do que mulheres trans. Homens trans virgens de tratamento possuem níveis séricos de testosterona maiores do que a mulheres cis.

Palavras-chave: Transexualismo; pessoas transgêneras; disforia de gênero; minorias sexuais e de gênero 


\begin{abstract}
OKANO, Sergio Henrique Pires Okano. Clinical and sociodemographical characteristics of a population with gender disorder/incongruence. $2020.87 \mathrm{f}$. Dissertação (Mestrado em Ciências - Faculdade de Medicina de Ribeirão Preto, Universidade de São Paulo, Ribeirão Preto, 2020.

Introduction: Gender incongruence (GI) is a condition in which a person's gender identity differs from the sex assigned at birth. An individual's initial perception of GI may occur at different ages. GI can lead to significant discomfort and the inability to integrate into society. Objective: To identify the age when individuals first perceive GI, and to compare the sociodemographic characteristics of those who are male-to-female $(\mathrm{MtF})$ and female-to-male (FtM) in a sample of subjects with GI, and to describe the outcomes of a follow-up on hormonal treatment. Methodology: Cross-sectional study based on a review of the medical records of individuals diagnosed with GI who visited the Gender Incongruence Clinic of Hospital das Clínicas de Ribeirão Preto (Brazil). Results: We identified 193 individuals with GI, 109 (56.5\%) of whom reported the first perception of GI during childhood. FtMs reported earlier perception of GI than MtFs (OR $=2.05, \mathrm{p}=0.02)$, and more students were FtMs than MtFs $(\mathrm{OR}=2.15, \mathrm{p}=0.03)$. All subjects who reported engaging in prostitution $(n=8)$, had sexually transmitted infections (STIs; $n=26$ ), and were HIV-positive $(n=22)$ were MtFs. Overall, subjects with GI had high prevalences of smoking (35.9\%), use of alcohol (18.1\%), and use of psychoactive substances $(11.9 \%)$. More MtFs than FtMs used hormonal self-medication prior to the first appointment (69.6\% vs. 32.3\%, OR: 4.87, p < 0.01). In FtM undergoing androgen treatment both estrogen and testosterone levels increased after initiation of treatment, and in $\mathrm{MtF}$ there was a decrease in testosterone leves after the treatment. High levels of testosterone was observed in FtM group prior treatment. Conclusion: The initial perception of GI mostly occurs during childhood, and occurs earlier in FtMs than MtFs. Relative to FtMs, MtFs reported more self-medication with hormones and had higher rates of prostitution, STIs, and HIV infection. FtM have higher serum testosterone levels than cis women.
\end{abstract}

Keywords: transsexualism, transgender people, gender dysphoria, sexual and gender minorities 


\section{LISTA DE TABELAS E FIGURAS}

Figura 1: Organograma amostral das pessoas com D/IG atendidas no AESH entre janeiro de 2010 e julho de 2018 .

Figura 2: Fase de vida em que ocorreu a percepção (\%) da D/IG por gênero em transexuais atendidos no AING de 2010 a julho de 2018

Figura 3: Organograma da prescrição de tratamento hormonal prescrita no AING..... 35

Figura 4: Concentrações séricas de estrogênio e de testosterona pré e pós tratamento hormonal em mulheres trans com estrogênio isolado $(n=14)$. 36

Figura 5: Concentrações séricas de estrogênio e de testosterona pré e pós tratamento hormonal em mulheres trans em uso de estrogênio associado a antiandrogênico $(n=37) .37$

Figura 6: Concentrações séricas de estrogênio e de testosterona pré e pós tratamento hormonal androgênica em Homens trans $(n=29)$. .38

Figura 7: Dispersão crescente das concentrações séricas de testosterona (T) em ng/dl em homens trans virgens de tratamento $(\mathrm{n}=25)$ 38

Tabela 1: Caracaterização sociodemográfica da amostra de pessoas com D/IG atendida no AING janeiro de 2010 a julho de 2018 . 


\section{LISTA DE ABREVIATURAS E SIGLAS}

AING Ambulatório de Incongruência de Gênero

ANTRA Associação Nacional de Travestis e Transexuais

AUDIT Teste para Identificação de Problemas Relacionados ao Uso de Álcool

CFM Conselho Federal de Medicina

D/IG Disforia e/ou Incongruência de gênero

DDS Distúrbios da Diferenciação Sexual

DG Disforia de gênero

DHEA Dehidroepiandrosterona

DP Desvio padrão

DRS Distrital Regional de Saúde

DSM V Manual Diagnóstico e Estatístico de Transtornos Mentais - $5^{\circ}$ edição

E Estrogênio

E+AA Estrogênio + anti-androgênico

EEC Estrogênio Equino Conjugado

GIDICS Gender Identity Disorder in Childhood Scale

HAC Hiperplasia Adrenal Congênita 
HCRP Hospital das Clínicas de Ribeirão Preto

HIV Vírus da imunodeficiência humana

IBGE Instituto Brasileiro de Geografia e Estatística

IC Intervalo de confiança

IG Incongruência de gênero

IST Infecções Sexualmente Transmissíveis

$\mathbf{N} \quad$ tamanho da amostra

OMS Organização Mundial de Saúde

RA Receptor de Androgênio

RE Receptores de estrogênio

SNC Sistema Nervoso Central

T Testosterona

UERJ Universidade Estadual do Rio de Janeiro

UFG Universidade Federal de Goiás

UFRS Universidade Federal do Rio Grande do Sul

USP Universidade de São Paulo 


\section{SUMÁRIO}

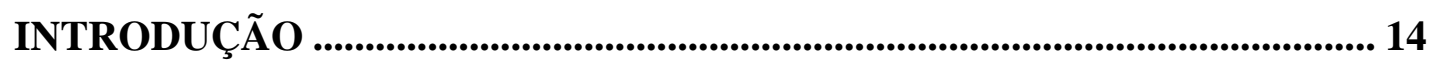

1. Definições:............................................................................................................. 14

2. Prevalência ................................................................................................................ 15

3. Etiologia .................................................................................................................... 16

3.1. Teoria da influência da ação hormonal sobre a D/IG.................................. 16

3.2. Teoria sobre as bases genéticas da $\mathrm{D} / \mathrm{IG}$.................................................. 17

3.3. Teoria sobre as bases sociais, psíquicas e ambientais da D/IG ................... 18

4. A autopercepção da D/IG ...................................................................................... 19

5. Condições sociais e de saúde da população com incongruência de gênero 20

6. Processo transexualizador ............................................................................................ 21

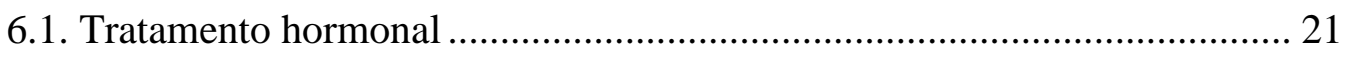

6.2. Cirurgia de Redesignação Sexual...…………………………………….... 22

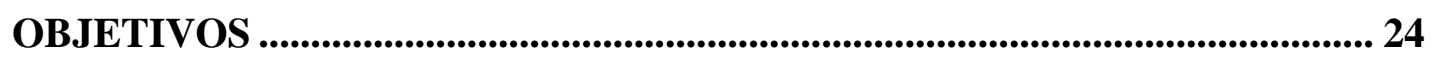

1. Principal................................................................................................................ 24

2. Secundários...................................................................................................................... 24

JUSTIFICATIVA ............................................................................................................ 25

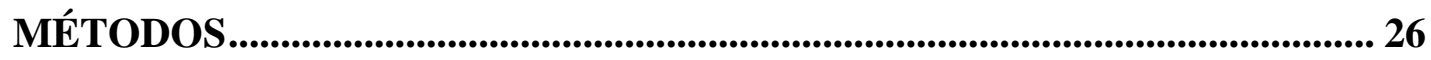

1. Critério de elegibilidade ............................................................................................... 29

2. Critério de exclusão ..................................................................................................... 29

3. Análise de dados........................................................................................................ 29 


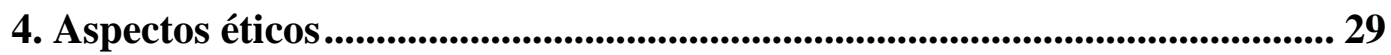

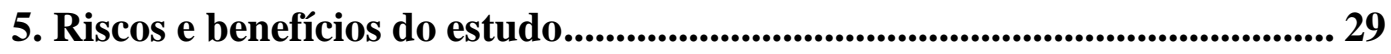

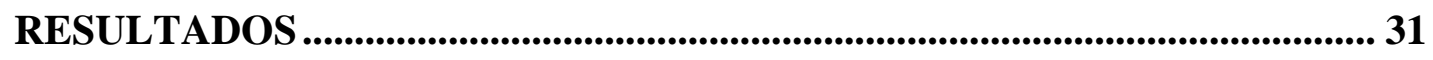

1. Avaliação sociodemográfica da amostra de pessoas com D/IG ................. 32

2. Avaliação do período de vida da percepção da D/IG ............................... 34

3. Avaliação da resposta hormonal ao tratamento hormonal......................... 35

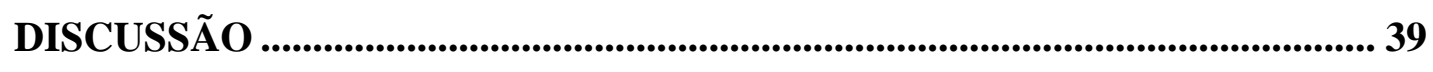

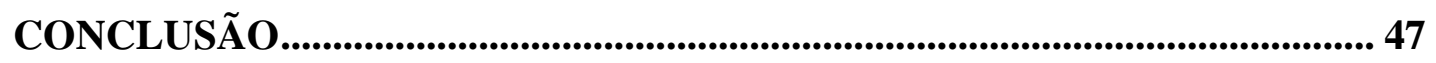

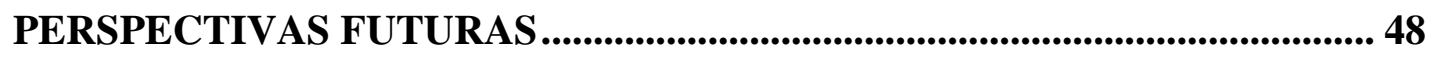

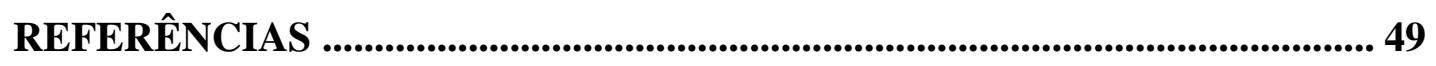

ANEXO A: Parecer consubstanciado do CEP ................................................60

ANEXO B: Aprovação do Projeto pelo Departamento de Ginecologia e

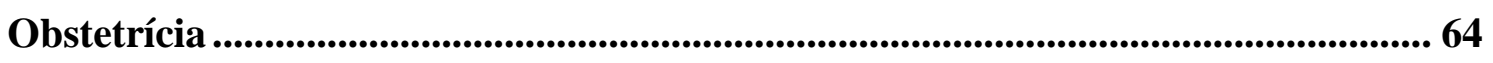

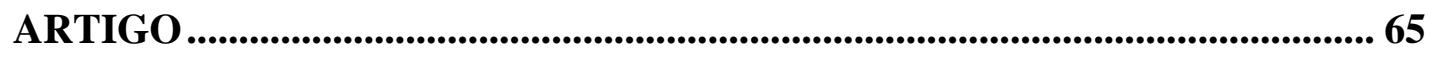




\section{INTRODUÇÃO}

\section{Definições:}

Para discutir a incongruência de gênero, primeiramente, é necessário entender a diferença entre gênero e sexo. Sexo é o termo utilizado para classificar em homem ou mulher pelas características sexuais primárias, presença de pênis ou vulva, por exemplo. Casos em que a diferenciação anatômica gera conflito podem ser classificados como Distúrbios da Diferenciação Sexual (DDS) (LEE, HOUK, et al., 2006). Gênero, por sua vez, tem uma definição mais social, perceptível, por exemplo, pelos tipos de vestimenta, corte de cabelo, atividades laborais que determinado sexo exerce (KROGER, 1997). A identidade de gênero é definida como a forma com que a pessoa se vê e vivencia o próprio gênero, sendo cis quando há congruência entre o gênero e o sexo designado; e trans, quando não há esta congruência (KOHLBERG, 1996).

A quinta edição do Manual Diagnóstico e Estatístico de Transtornos Mentais, publicado em 2014 (DSM-V, 2014) classifica a transexualidade como Disforia de Gênero enquanto a Classificação Internacional das Doenças (CID) - $11^{\text {a }}$. Edição, publicada em 2018, adota a terminologia Incongruência de Gênero (IG) em substituição ao termo transexualismo adotado na CID-10, que remetia a uma condição patológica (CID-11, 2018). .

Segundo o Manual Diagnóstico e Estatístico de Transtornos Mentais (DSM V, 2014):

"A disforia de gênero (DG) é definida pela incongruência acentuada entre o gênero experimentado/expresso e o gênero designado de uma pessoa, com duração de, pelo menos, seis meses, manifestada por, no mínimo, dois dos seguintes:

a) incongruência acentuada entre gênero experimentado/expresso e as características sexuais primárias e/ou secundárias;

b) forte desejo de livrar-se das próprias características sexuais primárias e/ou secundárias em razão de incongruência acentuada com o gênero experimentado/expresso;

c) forte desejo pelas características sexuais primárias e/ou secundárias do outro gênero;

d) forte desejo de pertencer ao outro gênero;

e) forte desejo de ser tratado como outro gênero;

f) forte convicção de ter os sentimentos e reações típicos do outro gênero (ou de algum gênero alternativo diferente do designado);

E a condição estar associada a sofrimento clinicamente significativo ou prejuízo no funcionamento social, profissional ou em outras áreas importantes da vida do indivíduo" (DSM-V, 2014).

De acordo com a CID-11 (CID-11, 2018), a IG em adolescentes e adultos é caracterizada pela aparente e persistente incongruência entre o gênero vivenciado pelo 
indivíduo e seu sexo designado ao nascimento, manifestado por, pelo menos, outras duas dessas características:

1) um forte sentimento de desconforto com suas características sexuais primárias ou secundárias, devido à incongruência com o gênero vivenciado;

2) um forte desejo de se livrar destas características incongruentes ao gênero vivenciado;

3) um forte desejo de ter características sexuais primárias ou secundárias do sexo vivenciado.

A incongruência de gênero na criança também é caracterizada pela acentuada incongruência entre o gênero vivenciado e o designado ao nascimento. Tal condição inclui um forte desejo de pertencer a um gênero diferente do sexo designado, uma forte aversão a sua anatomia sexual ou a caracteres sexuais secundários e/ou um forte desejo pelas características sexuais primárias ou secundárias que combinem com o sexo vivenciado. Brincadeiras de faz de conta e fantasias, brinquedos e jogos ou atividades e amigos pertencem ao gênero vivenciado mais do que ao sexo designado ao nascimento. A incongruência deve permanecer por ao menos 2 anos, sendo que o comportamento de variância e preferências de gênero isoladamente não fazem o diagnóstico (CID-11, 2018).

Por definição, considera-se homem trans a pessoa que se identifica como homem porém foi designado ao nascimento como do sexo biológico feminino, e mulher trans, a pessoa que se identifica como mulher porém foi designada ao nascimento como do sexo biológico masculino (ONU - NAÇÕES UNIDAS, 2013).

Como ambas as classificações são adotadas na literatura, neste trabalho utilizaremos a denominação Disforia e/ou Incongruência de gênero (D/IG).

\section{Prevalência}

Estudos que avaliam a prevalência da incongruência de gênero são heterogêneos na literatura. Um estudo americano da década de 60 evidenciou a prevalência de 1:100.000 em mulheres trans e 1:400.000 para homens trans (PAULY, 1968). Outro estudo realizado na Suécia, com dados de 20 anos de observação, demonstrou que a incidência é praticamente constante $(0,15$ a 0,17 para 100.000 habitantes acima dos 15 anos de idade), enquanto a prevalência é de 1:30.000 para mulheres trans e 1:100.000, para homens trans (LANDÉN, WALINDER e LUNDSTRÖM, 1996). Mais recentemente, uma revisão sistemática encontrou uma prevalência de 4,6 transexuais para 
100.000 indivíduos sendo de 6,8 mulheres trans e 2,6 homens trans para cada 100.000 pessoas, acredita-se que esse aumento na prevalência seja recorrente de uma maior aceitação social da condição (ARCELUS, BOUMAN e VAN DEN NOORTGATE, 2015).

\section{Etiologia}

A etiologia da D/IG é desconhecida. As teorias sobre a origem dessa condição derivam de estudos experimentais com animais e poucos com seres humanos que sugerem uma complexa interação entre fatores biológicos, ambientais e culturais (ROSENTHAL, 2014; SARASWAT, et al., 2015).

\subsection{Teoria da influência da ação hormonal sobre a D/IG}

$\mathrm{Na}$ vida intrauterina, a presença do cromossomo $\mathrm{Y}$, estimula o desenvolvimento de testículos, responsáveis pela produção de testosterona - hormônio que é convertido, perifericamente, em diidrotestosterona pela 5-alfa-redutase e promove o aparecimento das características masculinas (CLARKSON e HARLEY, 2002). Parte da testosterona produzida é convertida, pela aromatase intracelular, em estrogênio promovendo a masculinização e a defeminização cerebral ao se ligar aos receptores alfa e beta de estrogênio, respectivamente. Os ovários, em roedores fêmeas, permanecem quiescentes até o nascimento e, portanto, não produzem estrogênios, enquanto a alfa-fetoproteína impede a ligação do estrogênio materno nos seus receptores fetais, impedindo assim a masculinização e defeminização cerebral da prole (BAKKER, DE MEES, et al., 2006 ). Desta forma, acredita-se que esses níveis insuficientes de estrogênio, em ratas do sexo feminino, promoveriam a feminização cerebral em roedores (MCCARTHY, 2008), no entanto, tal mecanismo não é bem elucidado em primatas (WALLEN, 2005).

Em roedores, os esteroides sexuais influenciam a formação da substância branca, dos núcleos da base e do volume cerebral durante os primeiros dias de vida intrauterina (COLLADO, et al., 1998; GUILLAMÓN, et al., 1998). Na década de 50, um experimento demonstrou que a administração de testosterona na vida intra-uterina de roedores ocasionou, na vida adulta, maior comportamento de monta em relação à lordose nas proles do sexo feminino, o que é típico de proles do sexo masculino (PHOENIX, GOY, et al., 1959).

Em mulheres portadoras da Hiperplasia Adrenal Congênita (HAC), uma patologia que apresenta aumento das concentrações séricas de androgênios circulantes, a 
prevalência de D/IG é de 5,2\%, ou seja, maior do que na população (DESSENS, SLIJPER e DROP, 2005). Um estudo em crianças do sexo masculino sugeriu que a ação da testosterona contribui para uma maior predileção por brinquedos e brincadeiras relacionados a movimento (CAMPBELL e EATON, 1999). Paralelamente, crianças do sexo feminino com HAC também dedicam mais tempo aos brinquedos e às brincadeiras tipicamente masculinas do que meninas sem a patologia (BERENBAUM e HINES, 1992). Apesar da influência no comportamento e da maior prevalência da D/IG em mulheres com HAC, observa-se que esta exposição intrauterina à testosterona em meninas, na vida adulta, está mais associada à expressão de gênero e à orientação sexual homoafetiva do que à identidade de gênero em humanos (MEYER-BAHLBURG, et al., 2004; MEYER-BAHLBURG \& DROP, 2015).

Estudos envolvendo a ressonância magnética funcional demonstram diferenças estruturais no cérebro de pessoas com D/IG em relação ao sexo biológico, sendo a estrutura das regiões cerebrais (conhecidas como áreas de dimorfismo sexual da pessoa trans) mais parecida com aquelas do gênero vivenciado do que ao gênero designado ao nascimento (SOWELL, et al., 2007; SPIZZIRRI, et al., 2018).

\subsection{Teoria sobre as bases genéticas da D/IG}

Estudos sugerem uma possível predisposição genética relacionada à gênese da D/IG. Uma revisão de relatos de casos da literatura constatou concordância de $39,1 \%$ entre gêmeos monozigóticos quanto à D/IG, o que sugeriu uma associação genética para o desenvolvimento dessa condição (HEYLENS, DE CUYPERE, et al., 2012).

Atualmente, os estudos tentam encontrar associações entre a D/IG e possíveis polimorfismos de receptores dos esteroides sexuais e das enzimas capazes de sintetizar e metabolizar estes hormônios. Polimorfismo genético é a presença de uma determinada frequência alélica maior que $1 \%$ na população independentemente do tamanho desta sequência, do tipo de mutação sofrida ou das interferências expressadas sobre o indivíduo (THOMPSON \& THOMPSON, 2007).

Os receptores de estrogênio (RE) são classificados em RE $\alpha$ e RE $\beta$. O RE $\beta$ encontra-se em maior número no sistema nervoso central (SNC), e sua ativação está associada à defeminização cerebral em ratos machos, ou seja, à supressão de comportamentos tipicamente femininos (KUDWA, MICHOPOULOS, et al., 2006). Em humanos, a expressão de alelos curtos CAG do receptor de androgênio (RA) está associado à maior função deste receptor, ou seja, a sua presença aumenta a função da 
ligação da testosterona ao receptor, como ocorre, por exemplo, em algumas síndromes hiperandrogênicas em mulheres (RAZNAHAN, LEE, et al., 2010).

A avaliação de uma amostra de mulheres trans na Suécia encontrou que um alelo longo do RE $\beta$ está associado ao desenvolvimento da D/IG (HENNINGSSON, WESTBERG, et al., 2005). Outra amostra de 112 mulheres trans com 258 controles do sexo masculino, residentes nos Estados Unidos e na Austrália, evidenciou uma forte associação entre polimorfismo longo de sequência CAG do RA e mulheres trans (HARE, BERNARD, et al., 2009). Em contrapartida, um estudo com uma população de 242 japoneses trans não encontrou associação entre polimorfismo de RA, RE e da enzima CYP19A1, e a D/IG (UJIKE, OTANI, et al., 2009).

Em 2014, um grupo encontrou que a função do RE $\beta$ era diretamente proporcional ao tamanho do polimorfismo responsável pela codificação do seu receptor, indicando que, quanto maior o polimorfismo, maior a defeminização observada no cérebro da homens trans, porém, o mesmo grupo não encontrou associação entre os polimorfismos e mulheres trans, contrariando o resultado do grupo sueco (FERNÁNDEZ, ESTEVA, et $a l ., 2014)$. Diante da controvérsia de resultados encontrada nos estudos, foi proposto que, a condição trans em mulheres, poderia estar relacionada a uma interação inversa entre o tamanho das cadeias dos polimorfismos de RA e RE $\beta$, e não aos polimorfismos isoladamente em si. Desta forma, quando os receptores são traduzidos por um polimorfismo grande e o outro por um pequeno, aumenta-se a chance de desenvolvimento da condição trans em mulheres (FERNÁNDEZ, GUILLAMÓN, et al., 2018).

Apesar dos avanços dos estudos nesta área, as diferenças genéticas regionais das populações e ação dos esteroides sexuais depende de uma intensa e complexa interação destes hormônios com seus receptores e suas enzimas envolvidas no seu metabolismo, o que dificulta a universalização dos achados, no entanto não afasta a possibilidade de uma causa genética na gênesis da D/IG. (SWIFT-GALLANT e MONKS, 2017).

\subsection{Teoria sobre as bases sociais, psíquicas e ambientais da D/IG}

Existem várias teorias que tentam explicar a construção da identidade de gênero em uma perspectiva sociocultural e ambiental. Para o psicanalista Robert Stoller, a origem desta condição estaria na infância, e possivelmente seria consequência da não elaboração do complexo de Édipo devido à presença de uma mãe masculinizada, que invejaria os homens e desejaria ser um deles (conhecida como mãe Stolleriana), enquanto o pai passaria a ser uma figura de segundo plano na formação da criança do sexo masculino 
(STOLLER, 1982). Para Harry Benjamin, um endocrinologista e sexólogo alemão, a concepção de sexo deriva de uma complexa interação cromossomal ou genética, anatômica, psicológica, social e jurídico, e que o desenvolvimento "normal" se daria na congruência de todos esses fatores e que somente um ajuste físico (cirúrgico ou hormonal) poderia tornar a pessoa trans congruente, permitindo a vivência plena da sua sexualidade (BENJAMIN, 1966).

\section{A autopercepção da D/IG}

A manifestação de características da D/IG pode ocorrer na infância e são relatadas pelos familiares com frequência, mas ainda pouco se sabe sobre o momento em que ocorre a autopercepção desta condição. Vale aqui ressaltar que, na maioria das vezes, é na adolescência que ocorre a confirmação da D/IG (LOBATO MI, 2009). Uma avaliação realizada em um serviço no Brasil identificou que a autopercepção em homens trans da D/IG ocorreu, em média, aos 6 anos de idade com desvio padrão de 2 anos (CUNHA, 2013).

Coortes com crianças com diagnóstico de D/IG mostram que o diagnóstico não persiste na vida adulta, na maioria dos casos (STEENSMA, BIEMOND, et al., 2010). Embora as taxas de persistência sejam bastante variadas na literatura (2-27\%), os resultados demonstram que a maioria dos casos de sofrem remissão após a adolescência (STEENSMA, BIEMOND, et al., 2010). Wallien e Cohen Kettenis (2008) demonstraram que quanto mais extrema for a expressão da D/IG na infância, maior a chance de persistência desta condição na vida adulta (WALLIEN e COHEN-KETTENSIS, 2008) e que apesar da alta taxa de remissão da condição após a adolescência, são encontradas altas taxas de homossexualidade e bissexualidade na vida adultas nestas pessoas. (WALLIEN e COHEN-KETTENSIS, 2008). Em contrapartida, coortes com adolescentes com D/IG não demonstram alternância na identidade de gênero na vida adulta em relação a vida adulta (DE VRIES, STEENSMA, et al., 2010).

$\mathrm{O}$ acesso à internet e as mídias sociais contribuíram para maior visibilidade da D/IG, tornando sua identificação mais precoce (OLSHAN, 2016). Pollok propõe que o desenvolvimento do homem trans ocorre em três fases:

i) O senso crescente do que é gênero através da influência da escola, da puberdade, da sexualidade e da exposição a diferentes tipos de gênero; 
ii) $\mathrm{O}$ reconhecimento da identidade transexual e o crescente descontentamento com o sexo de nascimento;

iii) O ajuste social através de sua adaptação a vida como um homem trans (POLLOCK e EYRE, 2012).

\section{Condições sociais e de saúde da população com incongruência de gênero}

Um estudo realizado pelo nosso grupo demonstrou que as pessoas com o diagnóstico de D/IG apresentam maior risco para depressão e ansiedade, o que resulta em maiores taxas de ideação suicida e suicídio nesta população. Entre os fatores que contribuem para esse agravo estão a intolerância social e familiar e a insatisfação com o próprio corpo (LERRI, ROMÃO, et al., 2017).

Muitas são as barreiras que afetam o bem-estar psíquico e social das pessoas com incongruência de gênero. Muitos são expulsos de casa e vivenciam maior violência social e encontram dificuldades para encontrar emprego. Segundo a Associação Nacional de Travestis e Transexuais (ANTRA), 90\% desta população recorre em algum momento da vida à prostituição como fonte de renda (CUNHA, 2017). Com isto, ficam expostos ao maior risco de doença mental, de uso ilícito de drogas e exposição ao HIV (ECKER, e SYLVESTRE, 2017). De acordo com a Transgender survey, a prevalência de infecção pelo HIV entre transexuais é 5 vezes maior do que a prevalência na população geral (INSTITUTE OF MEDICINE, 2011), chegando a 25\% e mais prevalentes em grupos com idade mais avançada, moradores de áreas metropolitanas, com história de outras infecções sexualmente transmissíveis (ISTs) e que se prostituíram em algum momento da vida (COSTA, FONTANARI, et al., 2015 ). Em outra avaliação realizada no Rio de Janeiro, $31,2 \%$ da população de mulheres trans e travestis apresenta testes positivos para HIV e $7 \%$ delas não tinham conhecimento prévio deste diagnóstico; 28,9\% foram diagnósticas com sífilis, 14,6\%, com Chlamydia sp retal e 13,5\% com gonorreia (GRINSZTEJN, JALIL, et al., 2017).

Sabe-se que a tabagismo e etilismo são hábitos mais frequentes na população de adolescentes com D/IG do que dos congruentes (COULTER, BERSAMIN, et al., 2018 ). Na Nova Zelândia, o uso cigarro nas minorias de gênero está associado a consumo de outras substâncias e maior risco social devido a pobreza, marginalização e falta de suporte psicológico (DEACON e MOONEY-SOMERS, 2017 ). Em 2017, foi publicado o primeiro estudo nacional nos Estados Unidos, avaliando o uso de tabaco nos estados unidos em transexuais, que conclui tratar-se de uma população de maior risco para uso de 
tabaco (BUCHTING, EMORY, et al., 2017). A prevalência de tabagismo na população brasileira em 2013 era de 14,8\% (MINISTÉRIO DA SAÚDE, 2013), porém dados que envolvam a avaliação exclusiva da população trans nesta prevalência são escassos na literatura.

A prevalência de consumo abusivo de álcool é alta, porém as suas estimativas são muito variáveis entre os estudos sobre o tema (GILBERT, PASS, et al., 2018). Um estudo brasileiro evidenciou que o uso abusivo do álcool é prevalente entre os travestis (KERRCORRÊA, PINHEIRO, et al., 2017). Acredita-se que seja este um fator associado ao maior risco de relações sexuais desprotegidas e aumento da prevalência do HIV nesta população (KERR-CORRÊA, PINHEIRO, et al., 2017).

Quanto ao consumo de drogas e substâncias, a prevalência chega a ser de 2,5 a 4 vezes maior em comparação a população não trans (DAY, FISH, et al., 2017). Os transexuais mais jovens são mais vulneráveis ao consumo precoce dessas substâncias devido à grande vulnerabilidade emocional e social a que estão expostos e ao maior risco de distúrbio psiquiátrico com ansiedade e depressão que sofrem (DAY, FISH, et al., 2017).

\section{Processo transexualizador}

A adequação do fenótipo é crucial para a melhora da qualidade de vida da pessoa com D/IG (DE CUYPERE, T'SJOEN e BEERTEN, 2005) e envolve o tratamento hormonal e cirurgias para adequar o corpo da pessoa a sua identidade de gênero. $\mathrm{O}$ Processo Transexualizador no Brasil é regulamentado pela Portaria 2803/2013 do Ministério da Saúde, entre os critérios para o tratamento hormonal envolvem avalição psiquiátrica e acompanhamento psicológico e, obrigatoriamente, idade mínima de 16 anos para a hormonioterapia e 18 para a cirurgia, após pelo menos, um ano de acompanhamento psicológico autorizando o procedimento (MINISTÉRIO DA SAÚDE, 2011; CONSELHO FEDERAL DE MEDICINA, 2019)

\subsection{Tratamento hormonal}

O tratamento hormonal para o homem trans envolve a prescrição de testosterona e para a mulher trans envolve a prescrição do estrogênio associado ou não a drogas antiandrogênicas, como a espironolactona e a ciproterona, com o objetivo de reduzir a produção endógena de hormônios e de adequar características fenotípicas do gênero vivenciado (HEMBREE, 2017). 
O uso de estrogênios promove o aumento das mamas, aumento de depósito de gordura em região dos quadris e redução dos níveis de testosterona e o uso de testosterona tem o objetivo de aumentar a massa muscular, aumentar o clitóris e evidenciar caracteres sexuais secundários como o aumento de pelos e mudança no timbre da voz e os seus princípios são baseados na prescrição de tratamentos hormonais para pacientes com hipogonadismo (HEMBREE, 2017).

O uso de estrogênio está associado ao risco de desenvolvimento de doenças tromboembólicas, ao desenvolvimento de macroprolactinomas, câncer de mama, doença coronariana e cerebrovascular, colelitíase e hipertrigliciridemia, enquanto o uso de testosterona está associado ao alto risco de eritrocitose (hematócrito > 50\%), disfunção hepática, doença coronariana e cerebrovascular, hipertensão e câncer de mama e uterino, além de infertilidade transitória (HEMBREE, 2017).

Há uma discussão na literatura sobre a possibilidade de bloqueio do eixo hipotálamo-hipófise através do uso dos análogos de GnRH em crianças e adolescentes com o diagnóstico de D/IG com o objetivo de impedir o aparecimento de caracteres sexuais secundários (ROTH, 2002). Entre as vantagens do bloqueio do eixo do sexual com o análogo do GnRH, destaca-se a reversibilidade do tratamento. Entretanto, efeitos colaterais do tratamento como alterações emocionais, dano cognitivo, infertilidade e perda de massa óssea requerem cuidados especiais com a prescrição e melhores evidências sobre a segurança no que diz respeito ao seu uso a longo prazo (DELEMARRE-VAN DEN WALL e COHEN-KETTENIS, 2006). Como já discutido anteriormente, a maioria das crianças com D/IG não mantém o diagnóstico após puberdade, apesar de grande parte se apresentarem como homossexuais ou bissexuais na vida adulta, o que pode torna esta conduta passível de questionamento (WALLIEN e COHEN-KETTENIS, 2008).

\subsection{Cirurgia de Redesignação Sexual}

A primeira cirurgia realizada em um transexual que se tem documentação foi realizada em 1952 por Christian Hamburger, na Dinamarca. No Brasil, a primeira cirurgia foi realizada na paciente Waldyrene em 1971, sendo o médico responsável na época julgado por lesão corporal (PINTO e BRUNS, 2003). A adequação da mulher trans cirurgicamente afeta a fertilidade e consiste da penectomia, gonadectomia e criação da neovagina, sendo fístulas, prolapsos e estenoses, as principais complicações deste procedimento (HEMBREE, 2017). Enquanto a adequação do homem trans 
cirurgicamente é realizada através da mastectomia, panhisterecomia, colpectomia e faloplastia ou meatoplastia, sendo as duas últimas modalidades ainda consideradas experimentais (HAGE, DE GRAAF, et al., 1993). Atualmente, existem 5 serviços a nível nacional habilitados para realização dos procedimentos: Hospital de Clínicas de Porto Alegre (UFRS); Hospital Universitário Pedro Ernesto (UERJ); Hospital de Clínicas da Faculdade de Medicina da USP; Hospital das Clínicas de Goiânia (UFG) e Hospital das Clínicas da Universidade Federal de Pernambuco (MINISTÉRIO DA SAÚDE, 2017). Recentemente houve redução para idade mínima para o procedimento de 18 anos, sendo obrigatório o seguimento mínimo de 1 ano de acompanhamento psiquiátrico ou psicológico a fim de afastar condições psiquiátricas que impeçam a realização do procedimento (CONSELHO FEDERAL DE MEDICINA, 2019). 


\section{OBJETIVOS}

1. Principal

1. Identificar o período da vida em que as pessoas com D/IG perceberam a incongruência de gênero com o sexo que lhes foi designado ao nascimento.

\section{Secundários}

1. Avaliar as características clínicas e sociodemográficas da população trans.

2. Avaliar os níveis hormonais de homens e mulheres trans. 


\section{JUSTIFICATIVA}

A percepção da D/IG pode ocorrer em qualquer fase da vida. A designação do gênero da criança é dada com base no sexo biológico ao nascimento, no entanto, durante o seu desenvolvimento, a criança assume comportamentos relacionados à identidade de gênero vivenciada, independentemente de ser, biologicamente, homem ou mulher.

Identificar o momento em que ocorre a percepção da D/IG é importante para definir estratégias de cuidado para facilitar o processo de inserção social da pessoa trans, bem como como para a prevenção do aparecimento dos caracteres sexuais secundários a fim de minimizar os agravos decorrentes da constante exposição à vulnerabilidade social.

Identificar fatores sociais e demográficos, e avaliar os níveis terapêuticos alvo das dosagens hormonais prescritas no ambulatório para esta população podem auxiliar na confecção de um protocolo de atendimento, bem como sugerir novas pesquisas a fim de identificar doses terapêuticas específicas para esta população.

Descrever os dados relacionados ao acompanhamento hormonal é importante uma vez que ainda hoje são seguidos protocolos na adequação hormonal baseados no tratamento de pacientes cisgêneros (cis) com hipogonadismo, além da literatura trazer algumas controvérsias sobretudo na ação dos estrogênios e medicações antiandrogênicas sobre a testosterona em mulheres trans. 


\section{MÉTODOS}

Trata-se de um estudo misto, composto numa primeira fase por uma avaliação transversal com levantamento dos dados retrospectivos mediante revisão de prontuários de pessoas com diagnóstico de D/IG em seguimento no Ambulatório de Incongruência de Gênero (AING) do setor de Reprodução Humana da Faculdade de Medicina de Ribeirão Preto da USP que realizaram caso novo entre janeiro de 2010 e julho de 2018 e uma segunda fase composta de uma coorte, na qual foram avaliados as concentrações pré e pós-tratamento desta amostra.

O AING tem uma periodicidade semanal, funcionando às segundas-feiras pela manhã e às terças-feiras pela tarde e atende aproximadamente 15 pessoas com D/IG, semanalmente. A equipe de cuidado é composta por ginecologista, psiquiatra, psicólogo, fonoaudiólogo que trabalham em um modelo interdisciplinar oferecendo o processo transexualizador parcial: avaliação clínica, psiquiátrica e psicológica, tratamento hormonal e adequação da voz, sendo, os casos cirúrgicos, encaminhados para outro serviço.

Durante a investigação foram levantados todos os prontuários de pessoas com diagnóstico com D/IG agendados para caso novo (primeira consulta) no AING entre janeiro de 2010 e julho de 2018. Foram selecionados para a análise, 210 prontuários. Destes, 193 pessoas com D/IG compareceram ao ambulatório para o caso novo e puderam ter seus dados extraídos sendo 125 mulheres trans e 68 homens trans.

Um banco de dados foi elaborado contendo as seguintes variáveis para análise:

a) Idade no caso novo obtida através de numeral inteiro ordinal expresso em anos;

b) Exercício ou não de atividade laboral remunerada, expresso por reposta dicotômica (sim ou não) fornecidas no atendimento ou na ficha cadastral da pessoa com D/IG;

c) Presença de comorbidades para risco cardiovascular (p.e. doenças crônicas endócrinas, cardiovasculares e infeciosas, tais como diabetes mellitus, hipertensão arterial, doença coronariana, angina, dislipidemia e história de tromboses autoreferidas ou identificadas por exames e registrados em prontuários. Os dados foram registrados de forma dicotômica (sim ou não) para presença de doença que configure risco cardiovascular.

d) O diagnóstico de ISTs foi obtido através de informação obtida durante a anamnese, exame físico ou resultado laboratorial registrado no prontuário. Os 
dados foram registrados de forma dicotômica (sim ou não) conforme presença ou não de ISTs.

e) Hábitos como tabagismo, etilismo e uso de drogas ilícitas foram informados pela pessoa com D/IG durante o atendimento médico e foram registrados de forma dicotômica (

f) Informações referentes ao uso de hormônios previamente ao caso novo e tratamento proposto no ambulatório, bem como níveis hormonais de estrogênio e/ou testosterona dosados no HCRP foram fornecidas pela própria pessoa com D/IG e foram registras de forma dicotômica (sim ou não) conforme presença ou não de tratamento previo ao caso novo, respectivamente. As informações referentes ao tratamento proposto foram estratificadas em três grupos, independentemente da dose prescrita: pessoas que realizaram tratamento com estrogênio exclusivamente $(\mathrm{E})$, pessoas que realizaram tratamento com estrogênio associado a um anti-androgênio (E+AA) e pessoas que realizaram o tratamento com testosterona $(\mathrm{T})$.

g) As dosagens de estradiol foram realizadas utilizando o método de quimiluminescência pelo laboratório de Ginecologia e Obstetrícia e foram expressas em pg/ml, tendo a fase folicular como referência (normal até 160 $\mathrm{pg} / \mathrm{ml})$.

h) As dosagens de Testosterona foram realizadas através de radioimunoensaio pelo laboratório de Endocrionologia-Imunoensaios e seus resultados expressos em ng/dl, tendo valores de referência: masculino: 250 a $900 \mathrm{ng} / \mathrm{dl}$ e feminino de 20 a $80 \mathrm{ng} / \mathrm{dl}$.

i) O dado referente ao período de vida em que perceberam a incongruência foi obtido através da pergunta: "com que idade você percebeu que se sentia mulher? com que idade você percebeu que se sentia homem?”. As respostas poderiam conter a idade da percepção ou o período da vida "infância", "adolescência" ou "vida adulta" aferida na primeira consulta realizada pelo médico residente de Ginecologia e Obstetrícia. Para avaliação nas pessoas que informaram a idade em que perceberam a incongruência, foi considerada a definição estabelecida pela OMS que considera infância o período até os 10 anos de idade, adolescência o período entre 10 e 19 anos de idade, e a vida adulta o período superior a 19 anos de idade (WHO, 1986). 
Por se tratar de uma revisão de prontuários, todas as informações são fiéis aos relatos das pessoas com D/IG ou informações contidas no prontuário, e, portanto, sujeitas a viés de detecção e/ou diagnóstico, uma vez que possa haver subnotificação de informações ou ocultamento por parte do informante. 


\section{Critério de elegibilidade}

Foram considerados para análise todos os prontuários de pessoas com D/IG que realizaram caso novo no AING solicitando o tratamento hormonal isolada ou associada à cirurgia para a adequação do fenótipo ao gênero de identificação.

\section{Critério de exclusão}

Foram excluídos do levantamento os prontuários que não continham minimamente os dados para as análises propostas, referente às pessoas que não realizaram caso novo na instituição.

\section{Análise de dados}

Os dados estão demonstrados por meio de tabelas e de gráficos. As variáveis qualitativas estão descritas considerando as frequências absolutas e relativas, enquanto variáveis quantitativas estão expressas por meio de medidas de posição central e de dispersão. Na comparação das variáveis categóricas foi utilizado o teste do qui-quadrado.

\section{Aspectos éticos}

Este projeto foi submetido ao Comitê de ética em pesquisa do Hospital das Clínicas da Faculdade de Medicina de Ribeirão Preto, Universidade de São Paulo. As atividades práticas deste projeto estão pautadas segundo as normas éticas pela Resolução 466/2012 do Conselho Nacional de Saúde sobre pesquisas com Ser Humano e foi solicitado e autorizada a dispensa do termo de consentimento por se tratar de coleta de dados de prontuários, uma vez que não seria possível a localização e recrutamento de todas as pessoas com D/IG avaliadas na pesquisa.

\section{Riscos e benefícios do estudo}

Considerando que o estudo é conduzido através de análise de informações obtidas em prontuários, para evitar o risco de perda de confidencialidade dos dados, os autores codificaram - e mantiveram sob sigilo dos pesquisadores - os dados de identificação. Por outro lado, a determinação da prevalência de comorbidades e fatores de risco associados a essa população, bem como identificar momento de reconhecimento da D/IG nesta

população, podem melhorar as políticas assistencialistas a este grupo, além de 
proporcionar embasamento científico para definição e consolidação dos protocolos clínicos assistenciais a serem adotados. 


\section{RESULTADOS}

Foram avaliados 193 prontuários de pessoas com diagnóstico de D/IG, dentre 210 agendados para caso novo entre janeiro de 2010 e julho de 2018. Dezessete prontuários foram excluídos da análise pois pertenciam a pessoas que foram agendados, mas não compareceram para o caso novo (Figura 1).

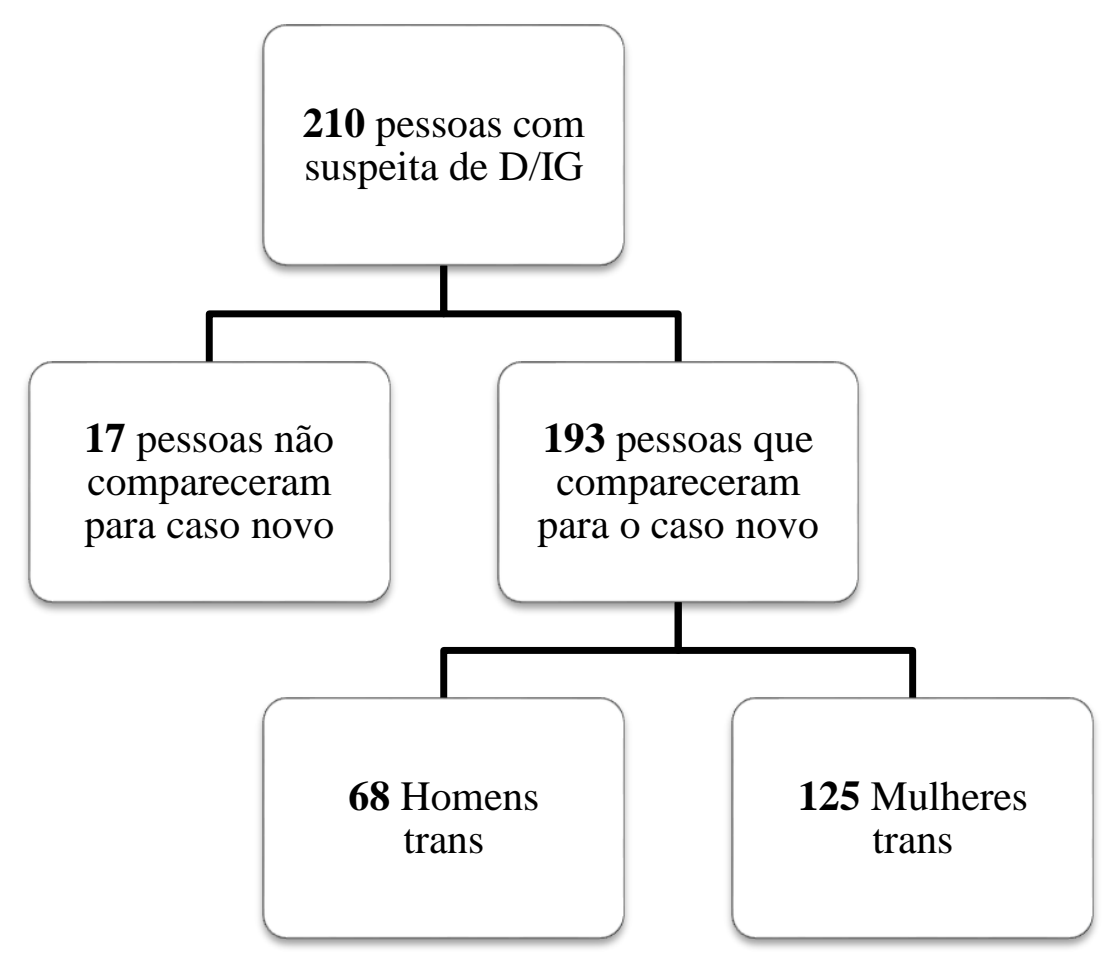

Figura 1: Organograma amostral das pessoas com D/IG atendidas no AING entre janeiro de 2010 e julho de 2018. 


\section{Avaliação sociodemográfica da amostra de pessoas com D/IG}

Dos 193 prontuários analisados, $125(64,8 \%)$ se identificaram como mulheres trans e $68(35,2 \%)$ se identificaram como homens trans. A idade média das mulheres trans foi de $27 \pm 9$ anos e dos homens trans foi de 27,2 $\pm 9,2$ anos.

Estratificando essa idade por faixas etárias na admissão do caso novo do ambulatório, $17(8,8 \%)$ pacientes tinham menos de 18 anos, sendo $11(8,8 \%)$ mulheres trans e $6(8,8 \%)$ homens trans. Cento e vinte e nove (66,8\%) tinham entre 18 e 29 anos, sendo $75(60,0 \%)$ mulheres trans e $54(79,4 \%)$ homens trans. Quarenta e três $(22,3 \%)$ tinham entre 30 e 50 anos, sendo $36(28,8 \%)$ mulheres trans e $7(10,3 \%)$ homens trans. E, finalmente, $4(2,1 \%)$ pessoas com D/IG tinham mais de 50 anos, sendo $3(2,4 \%)$ mulheres trans e $1(1,5 \%)$ homens trans (tabela 1$)$.

Cento e vinte e oito pessoas com D/IG (66.3\%) referiram exercer algum tipo de atividade remunerada e, destes, $8(4,1 \%)$ informaram que esta atividade era exclusivamente ou preferencialmente a prostituição, todos mulheres trans. Trinta e seis $(18,7 \%)$ eram estudantes sendo $18(26,5 \%)$ homens trans e $18(14,4 \%)$ mulheres trans $(\mathrm{OR}=2,15, \mathrm{p}=0,03)($ tabela 1$)$.

Quinze $(12,0 \%)$ mulheres trans e $5(7,4 \%)$ homens trans reportaram serem portadores de doenças crônicas endócrinas, cardiovasculares e infeciosas, tais como diabetes mellitus, hipertensão arterial, doença coronariana, angina, dislipidemia e história de tromboses autoreferidas ou identificadas por exames e registrados em prontuários. Ansiedade e depressão foram autorreferidos ou identificados na avaliação psiquiátrica com diagnósticos em $19(9,8 \%)$ pessoas da amostra, sendo $11(8,8 \%)$ mulheres trans e 8 $(11,8 \%)$ homens trans $(\mathrm{p}=0,51)$. (tabela 1$)$.

Quanto a presença de infecções sexualmente transmissíveis (ISTs), 26 (13,5\%) referiam diagnóstico, apresentaram lesão clínica ou positividade em sorologias. Destes casos, todos pertenciam ao grupo das mulheres trans (20,8\%). O HIV foi diagnosticado em $22(17,6 \%)$ das mulheres trans. Nenhum homem trans relatou infecção pelo HIV (tabela 1). 
Tabela 1: Caracaterização sociodemográfica da amostra de pessoas com D/IG atendida no AING janeiro de 2010 a julho de 2018.

\begin{tabular}{|c|c|c|c|c|}
\hline Variável avaliada & $\begin{array}{l}\text { Total } \\
\text { N }(\%)\end{array}$ & $\begin{array}{c}\text { Mulheres } \\
\text { trans N(\%) }\end{array}$ & $\begin{array}{c}\text { Homens trans } \\
\text { N (\%) }\end{array}$ & $\begin{array}{c}\text { p } \\
\text { valor }\end{array}$ \\
\hline Distribuição & $193(100)$ & $125(64,8)$ & $68(35,2)$ & \\
\hline \multicolumn{5}{|l|}{ Idade (anos) } \\
\hline$<18$ & $17(8,8)$ & $11(8,8)$ & $6(8,8)$ & \\
\hline $18-29$ & $129(66,8)$ & $75(60,0)$ & $54(79,4)$ & \\
\hline 30 aos 50 & $43(22,3)$ & $36(28,8)$ & $7(10,3)$ & \\
\hline$>50$ & $4(2,1)$ & $3(2,4)$ & $1(1,5)$ & \\
\hline \multicolumn{5}{|l|}{ Status de trabalho } \\
\hline Empregados & $128(66,3)$ & $88(70,4)$ & $40(58,8)$ & 0,10 \\
\hline Prostituição & $8(4,1)$ & $8(6,4)$ & $0(0)$ & $\mathbf{0 , 0 3}$ \\
\hline Estudantes & $36(18,7)$ & $18(14,4)$ & $18(26,5)$ & $\mathbf{0 , 0 3}$ \\
\hline Desempregados & $29(15,0)$ & $19(15,2)$ & $10(14,7)$ & 0,92 \\
\hline \multicolumn{5}{|l|}{ Avaliação Clínica } \\
\hline Risco cardiovascular & $20(10,3)$ & $15(12,0)$ & $5(7,4)$ & 0,31 \\
\hline Ansiedade/Depressão & $19(9,8)$ & $11(8,8)$ & $8(11,8)$ & 0,51 \\
\hline ISTs & $26(13,5)$ & $26(20,8)$ & $0(0)$ & $<0,01$ \\
\hline HIV & $22(11,4)$ & $22(17,6)$ & $0(0)$ & $<0,01$ \\
\hline Tabagismo & $50(35,9)$ & $27(21,6)$ & $23(33,8)$ & 0.06 \\
\hline Etilismo & $35(18,1)$ & $22(17,6)$ & $13(19,1)$ & 0.79 \\
\hline Drogadição & $23(11,9)$ & $17(13,6)$ & $8(11,7)$ & 0.71 \\
\hline $\begin{array}{l}\text { Tratamento } \\
\text { hormonal prévio }\end{array}$ & $109(56.5)$ & $87(69.6 \%)$ & $22(32,3)$ & $<0,01$ \\
\hline
\end{tabular}

Em relação aos hábitos, $50(35,9 \%)$ da amostra referiram uso de cigarro, sendo 27 $(21,6 \%)$ mulheres trans e $23(33,8 \%)$ homens trans $(\mathrm{p}=0,06)$. Quanto ao etilismo, 35 $(18,1 \%)$ pessoas com D/IG referiram realizar ingestão regular de álcool, sendo $22(17,6)$ mulheres trans e $13(19,1 \%)$ homens trans $(\mathrm{p}=0,79)$. O uso de drogas recreativo ou regular foi autorreferido por $23(11,9 \%)$ das pessoas com D/IG, sendo $17(13,6 \%)$ homens trans e $8(11,7 \%)$ mulheres trans $(\mathrm{p}=0,71)$ (tabela 1$)$. 
Ao todo, 109 (56,5\%) pessoas com D/IG chegaram ao ambulatório em tratamento hormonal sendo $87(69,6 \%)$ mulheres trans e $22(32,3 \%)$ homens trans $(\mathrm{OR}: 4,87, \mathrm{p}<0,01)$ (tabela 1).

\section{Avaliação do período de vida da percepção da D/IG}

Sobre a idade da percepção da D/IG, 109 (56,5\%) pessoas referiram a percepção desde a infância, $37(19,2 \%)$ se percebeu com D/IG na adolescência, 14 (7,2\%), na vida adulta e $33(17,1 \%)$ não souberam informar sobre o período da percepção da D/IG.

$\mathrm{Na}$ avalição dos homens trans, $63(50,4 \%)$ referiam a percepção da D/IG na infância, 29 (23,2\%) perceberam-se homens na adolescência, 7 (5,6\%) na vida adulta e $26(20,8 \%)$ não souberam informar sobre o período da percepção. Em relação as mulheres trans, $46(67,6 \%)$ referiram a percepção da D/IG na infância, 8 (11,8\%) na adolescência, $7(10,3 \%)$ na vida adulta e $7(10,3 \%)$ não souberam informar sobre o período de percepção (Figura 2). Homens trans percebem mais cedo a D/IG em relação às mulheres trans (OR: $2.05, \mathrm{p}=0,02)$.

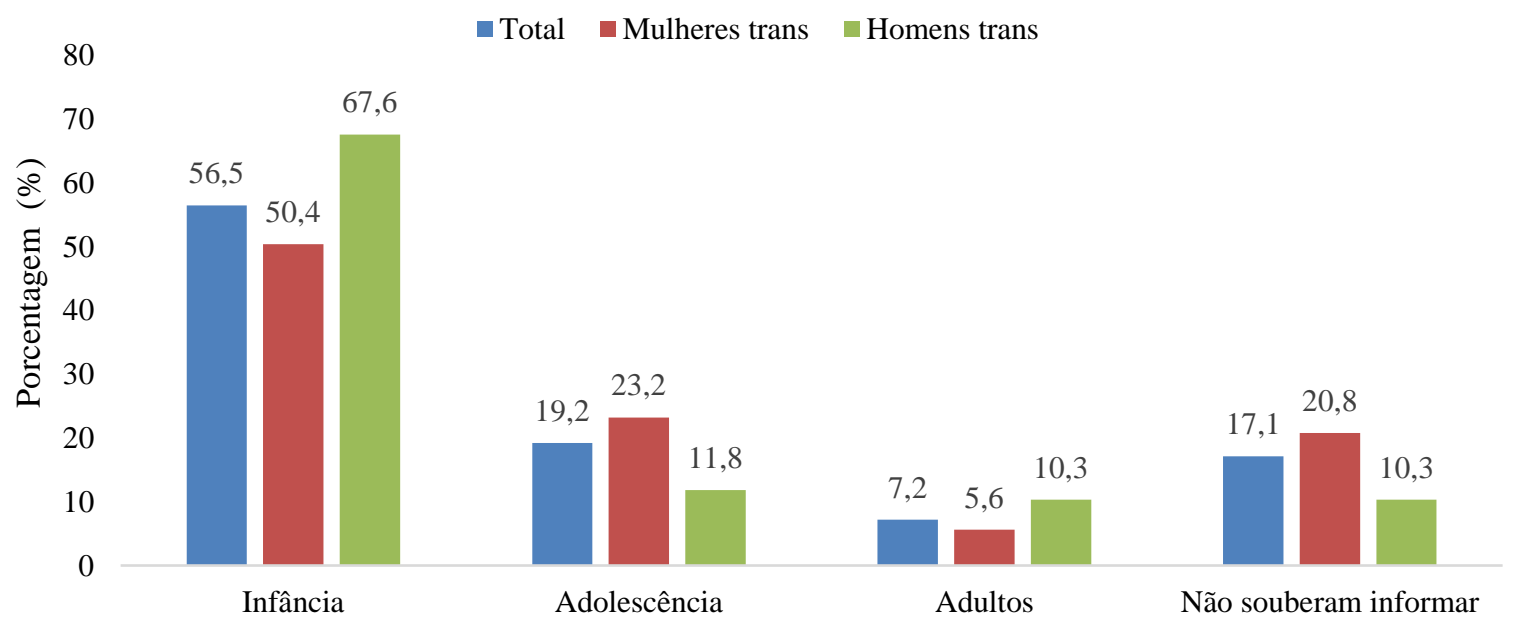

Fase da Vida de Percepção

Figura 2: Fase de vida em que ocorreu a percepção (\%) da D/IG por gênero em transexuais atendidos no AING de 2010 a julho de 2018. 


\section{Avaliação da resposta hormonal ao tratamento hormonal}

Cento e cinquenta $(77,7 \%)$ pessoas da amostra tinham idade maior ou igual a 18 anos, desejaram e preencheram os critérios para início do tratamento hormonal (figura 3). Das 193 pessoas avaliadas, 17 eram menores de idade e 26 não preenchiam condições para terapia hormonal tais como não retornar para consulta após exames, ou não ter colhido exames, ou apresentar alguma contra-indicação ao tratamento proposto ou dificuldade de acesso às medicações, resultando na amostra de 150 pessoas trans. A mediana da idade destes foi de 25 anos; nas mulheres trans, a mediana foi de 26 anos e nos homens trans, 23 anos.

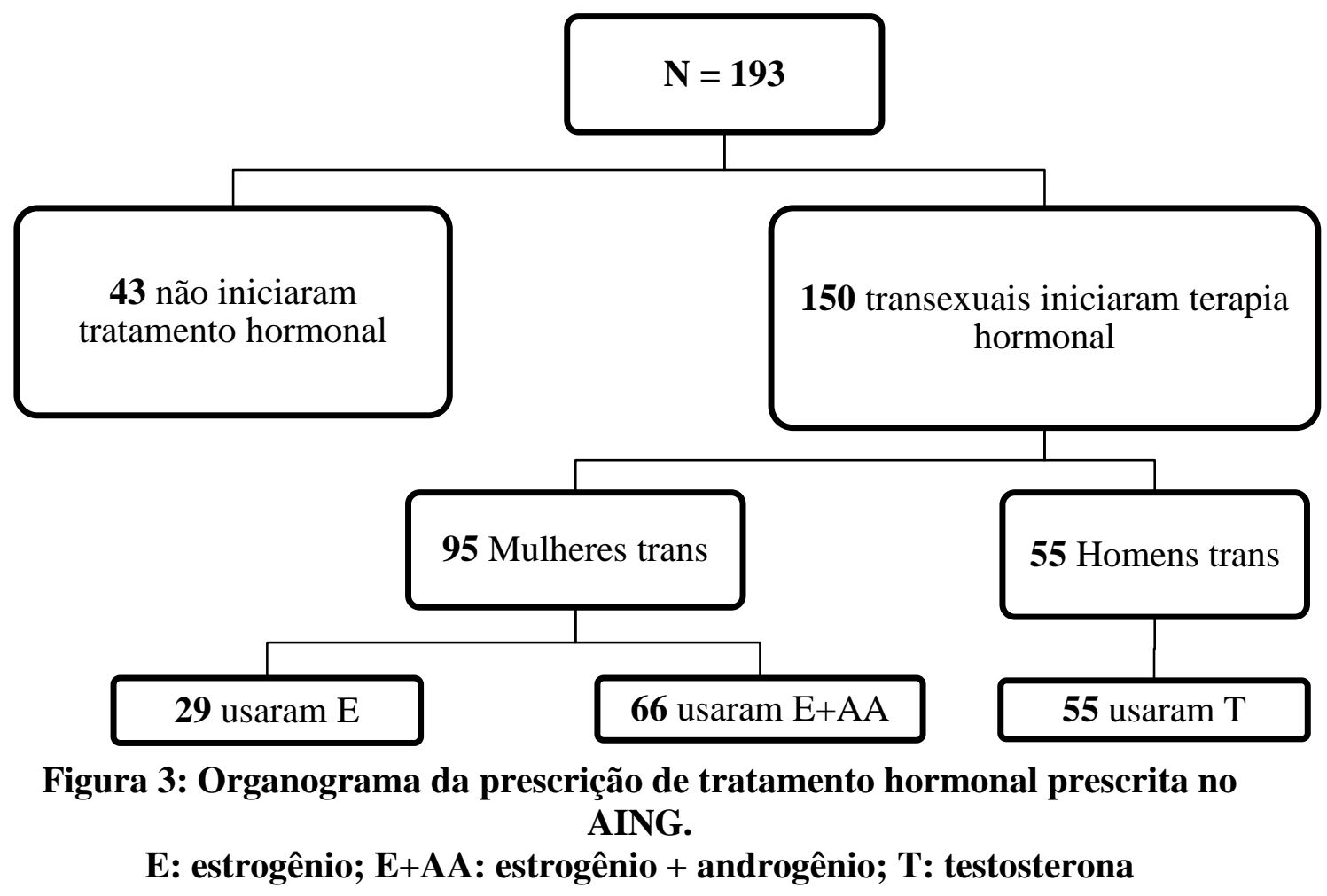

Das 95 mulheres trans avaliadas, $22(23,2 \%)$ eram virgens de tratamento. Vinte e nove $(30,5 \%)$ pessoas realizam tratamento com estrogênio e $66(69,5 \%)$ realizaram tratamento com estrogênio associado à medicação anti-androgênica. Dos 55 homens trans avaliados, $41(74,5 \%)$ eram virgens de tratamento. Para todos eles, foram prescritas formulações à base de testosterona (figura 3).

Em mulheres trans submetidas ao tratamento com estrogênio isoladamente, 14 $(48,3 \%)$ possuíam dosagens pré e pós tratamento hormonal. A mediana da concentração de estrogênio sérico deste grupo pré-tratamento foi de $56,7 \mathrm{pg} / \mathrm{mL}$ e a de testosterona, 
113,0 ng/dl. A mediana da concentração de estrogênio sérico após a intervenção foi de 94,2 $\mathrm{pg} / \mathrm{mL}$ e a de testosterona, $134,5 \mathrm{ng} / \mathrm{dl}$. Os resultados são representados na forma de boxplot na Figura 4 em quartis, média, mediana, valores mínimos e máximos.
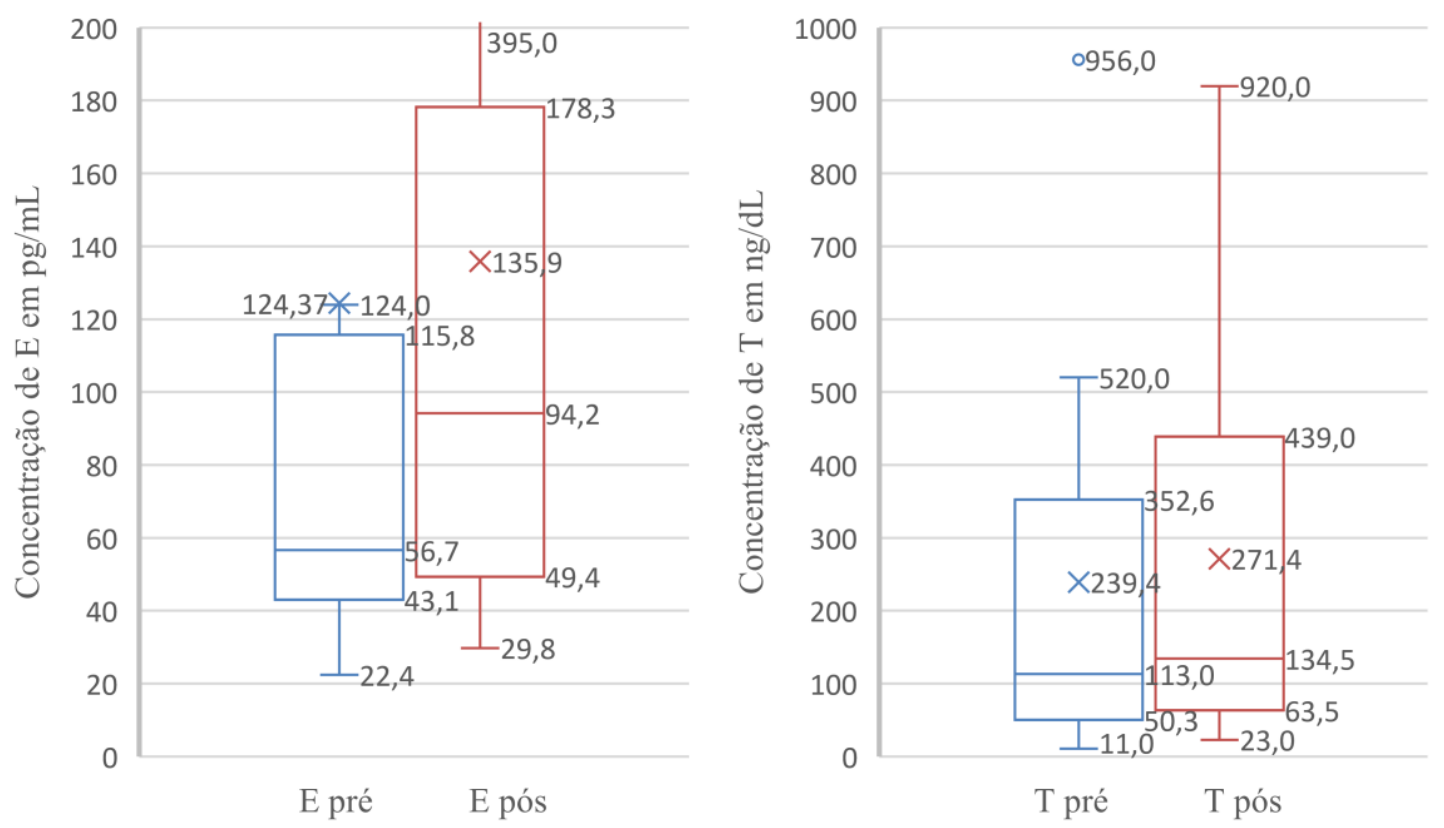

Figura 4: Concentrações séricas de estrogênio e de testosterona pré e pós tratamento hormonal em mulheres trans com estrogênio isolado $(n=14) . E$ : estrogênio $(\mathrm{pg} / \mathrm{mL})$; $\mathrm{T}$ : testosterona $(\mathrm{ng} / \mathrm{dL})$

Duas mulheres trans eram virgens de tratamento neste grupo e realizaram seguimento no ambulatório por mais de 2 anos. A mediana pré-tratamento de estrogênio foi de $29.8 \mathrm{pg} / \mathrm{ml}$ e da testosterona de $336 \mathrm{ng} / \mathrm{dl}$; enquanto a mediana pós-tratamento de estrogênio e testosterona foram, respectivamente, $56,5 \mathrm{pg} / \mathrm{ml}$ e $442 \mathrm{ng} / \mathrm{dL}$.

Das 66 mulheres trans que receberam o tratamento com estrogênio associado aos antiandrogênios, $37(56,1 \%)$ tinham dosagens pré e pós tratamento hormonal. A concentração de estrogênio pré-tratamento neste grupo teve mediana 45,20 pg/ml e a de testosterona $330 \mathrm{ng} / \mathrm{dl}$. Após a intervenção, este grupo apresentou a mediana da concentração de estrogênio de 70,3 pg/ml e 129 ng/dl para testosterona. Os resultados são representados na forma de boxplot na Figura 5 (abaixo) com quartis, média, mediana, valores mínimos e máximos. 

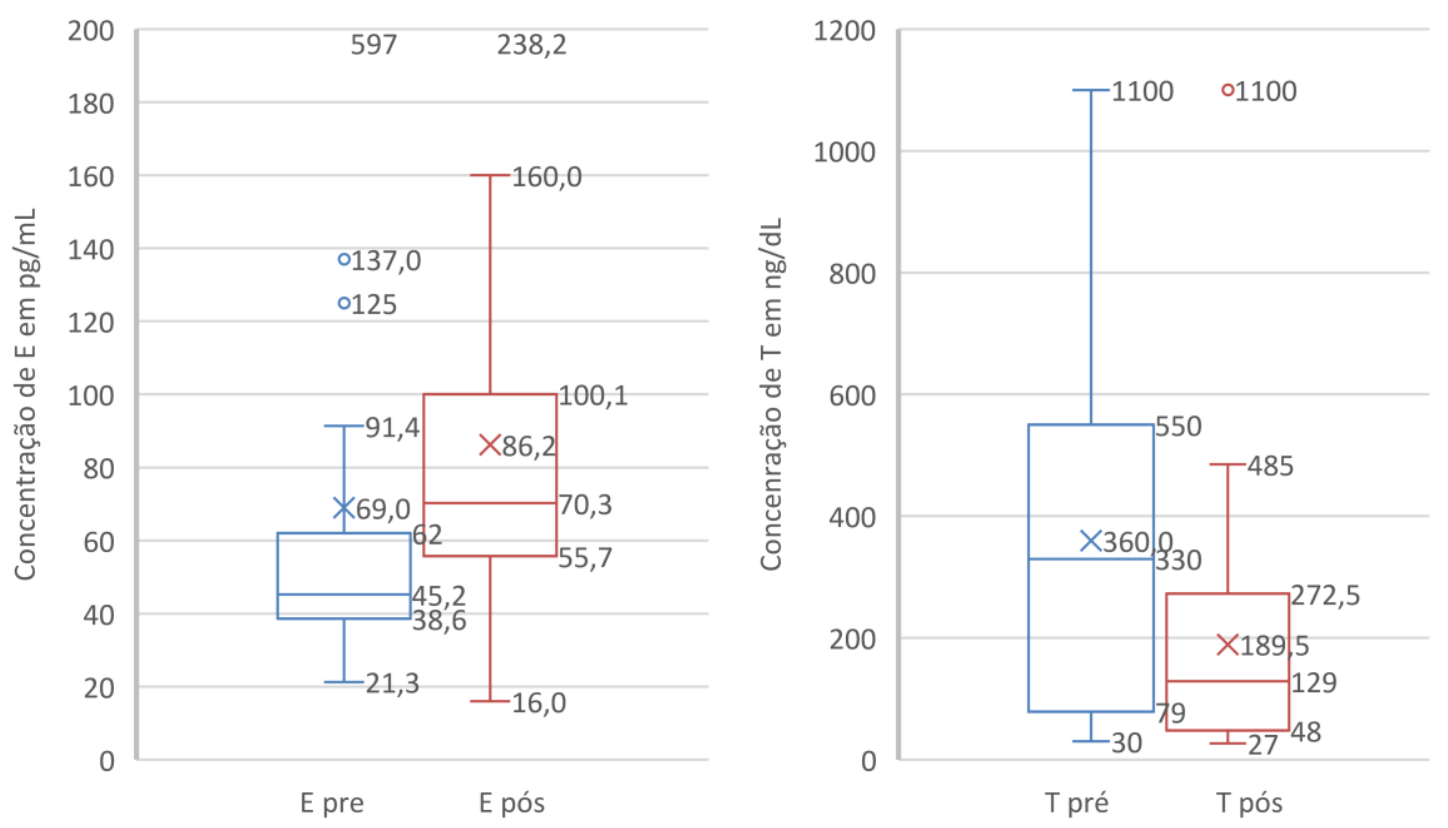

Figura 5: Concentrações séricas de estrogênio e de testosterona pré e póstratamento hormonal em mulheres trans em uso de estrogênio associado a antiandrogênico $(n=37)$.

E: estrogênio $(\mathrm{pg} / \mathrm{mL}) ; \mathrm{T}$ : testosterona $(\mathrm{ng} / \mathrm{dL})$

Sete mulheres trans em uso de estrogênio associado a medicações antiandrogênicas eram virgens de tratamento. As concentrações de estrogênio pré e pósintervenção nestes pacientes apresentam mediana, respectivamente, de 43,2 pg/ml e de $48,1 \mathrm{pg} / \mathrm{ml}$. Enquanto as concentrações de testosterona pré e pós intervenção tiveram mediana de $332 \mathrm{ng} / \mathrm{dl}$ e $205 \mathrm{ng} / \mathrm{dl}$, respectivamente.

Entre os homens trans que foram submetidos ao tratamento com testosterona, 29 $(52,7 \%)$ indivíduos tinham níveis de testosterona documentados pré e pós-tratamento. As concentrações séricas de estrogênio pré e pós-tratamento tiveram mediana de $55,1 \mathrm{pg} / \mathrm{ml}$ e $65,4 \mathrm{pg} / \mathrm{ml}$, respectivamente, e as concentrações séricas de testosterona pré e póstratamento tiveram mediana de $115 \mathrm{ng} / \mathrm{dl}$ e $400 \mathrm{ng} / \mathrm{dl}$, repectivamente. Os resultados são representados na forma de boxplot na Figura 6 (abaixo) em quartis, média, mediana, valores mínimos e máximos. 

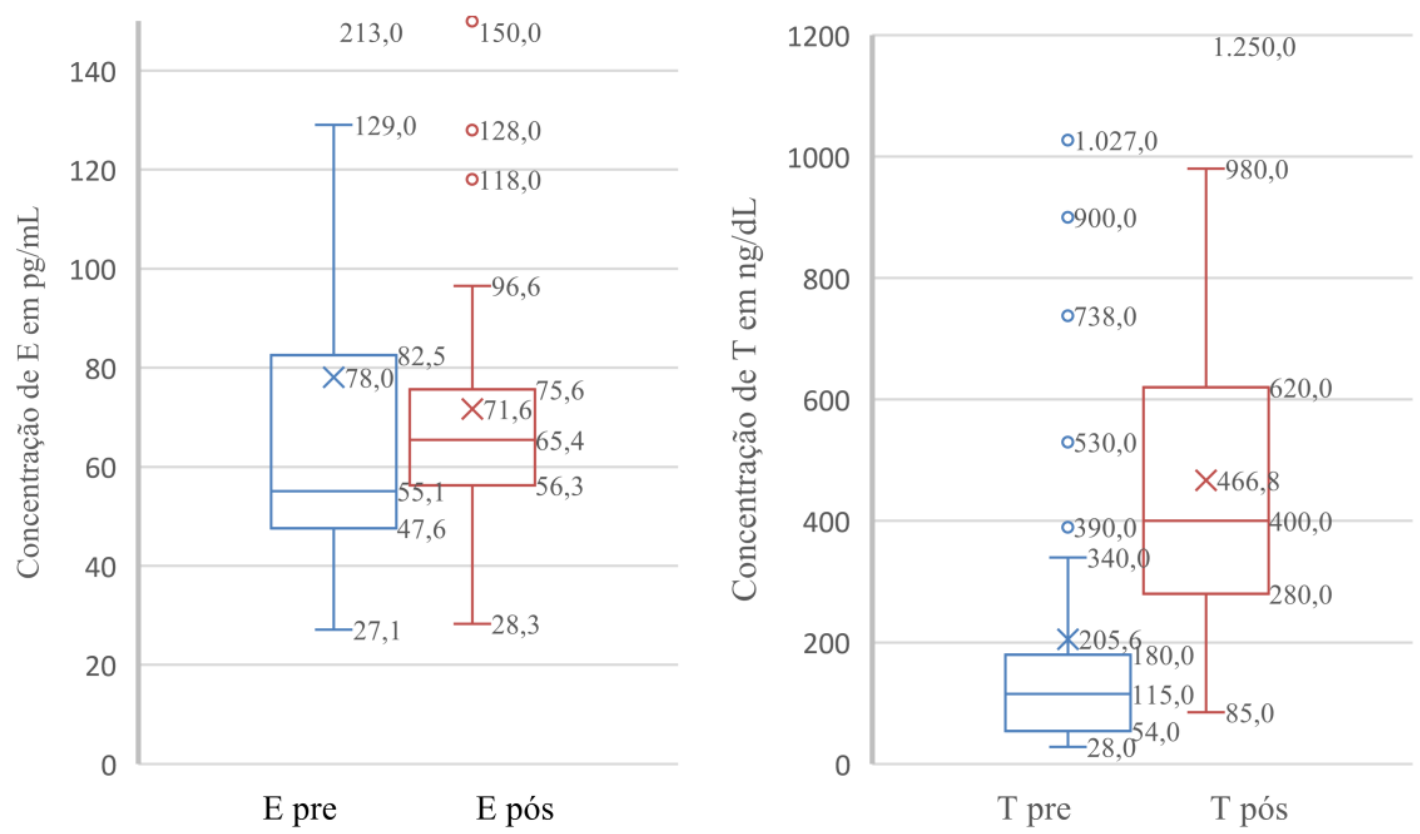

Figura 6: Concentrações séricas de estrogênio e de testosterona pré e póstratamento hormonal androgênica em Homens trans $(n=29)$. E: estrogênio (pg/mL); T: testosterona (ng/dL)

Vinte e cinco homens trans, com idade média de 22,4 $\pm 3,9$ anos, eram virgens de tratamento na amostra avaliada. A média da concentração de testosterona sérica nessa amostra foi de 76,6 ng/dL (IC 95\% = $61-92,3 \mathrm{ng} / \mathrm{dL}$ ) (figura 7). Quatorze pessoas possuíam níveis de testosterona acima de $60 \mathrm{ng} / \mathrm{dL}$ e cinco preenchiam critérios para diagnóstico de síndrome dos ovários micropolicísticos.

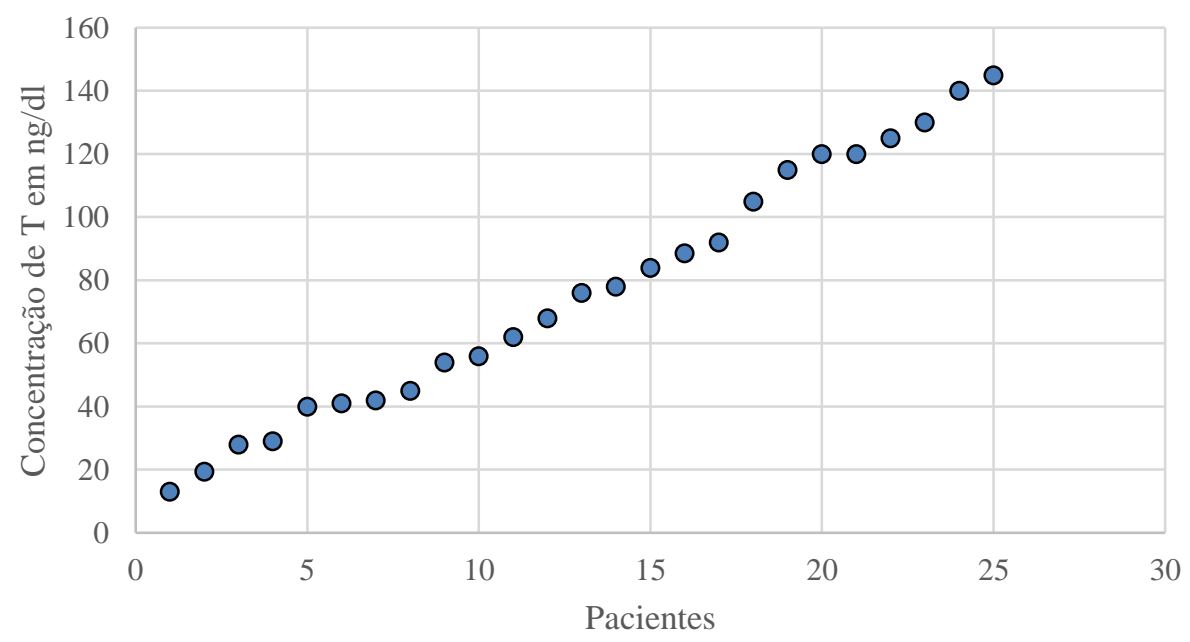

Figura 7: Dispersão crescente das concentrações séricas de testosterona (T) em $\mathrm{ng} / \mathrm{dl}$ em homens trans virgens de tratamento $(\mathrm{n}=25)$. 


\section{DISCUSSÃO}

O presente estudo teve como objetivo identificar o momento de vida em que as pessoas transexuais percebem a D/IG, avaliar as características clínicas e sociodemográficas da amostra e avaliar os níveis hormonais de homens e mulheres trans.

A amostra do nosso estudo, foi composta por 125 (64,8\%) mulheres trans e 68 $(35,2 \%)$ homens trans, em uma proporção de quase 3:2. Essa proporção entre os dois gêneros é superior ao sugerido pelas estatísticas anteriores (Arcelus, et al., 2015; Landén, et al., 1996; Pauly, 1968). Esse aumento na proporção de homens trans observado na amostra pode ser reflexo de como ocorrem os encaminhamentos ao AING, na maioria das vezes, via médicos ginecologistas da rede pública da distrital regional de saúde (DRS) de Ribeirão Preto, que normalmente recebem os pacientes homens trans para consulta por estes nascerem, biologicamente, mulheres. Outra hipótese decorre do fato de as mulheres trans realizarem automedicação, uma vez que não necessitam de receita para obterem acesso a tratamento hormonal (MINISTÉRIO DA SAÚDE, 2015). O acesso legalizado à testosterona requer receita médica, e, portanto, atendimento médico, ocasionando maior procura por este grupo ao ambulatório, o que pode resultar numa maior proporção de homens trans em seguimento no AING.

Em geral, os pacientes chegaram ao nosso serviço já em uso de medicamentos e na idade adulta, possivelmente, devido ao desconhecimento de serviços de acolhimento e atendimento e a própria dificuldade de acesso ao sistema de saúde pelo preconceito de profissionais e medo da discriminação. Existem estudos demonstrando as dificuldades do acesso da população trans ao sistema de saúde e sua permanência (BENTO, 2006; BENTO, 2012), o que afeta diretamente os princípios de equidade, integralidade e universalidade do SUS, apesar da portaria 2.836 de $1^{\circ}$ de Dezembro de 2011 que institui promoção integral às minorias de gênero. (BRASIL. MINISTÉRIO DA SAÚDE, 2013).

Dois-terços da nossa amostra referiu exercer algum tipo de atividade remunerada, somente foi baixa a prevalência de prostituição (4,2\%). Segundo a Associação Nacional de Travestis e Transexuais (ANTRA), 90\% desta população recorre em algum momento da vida à prostituição como fonte de renda (CUNHA, 2017). Em 2015, neste mesmo ambulatório, um estudo transversal com entrevista semiestruturada encontrou que 8 $(18 \%)$ dos transexuais atendidos neste ambulatório referiam estar na prostituição (LERRI, ROMÃO, et al., 2017). Curiosamente, apenas oito permanecem com registro de profissional do sexo em seus prontuários no caso novo desde então. Por outro lado, Lerri, em avaliação realizada neste mesmo serviço, encontrou que metade do pacientes 
atendidos no ambulatório recebia entre 1 e 3 de um salários mínimos ao mês e que $25 \%$ recebia mais de 3 salários mínimos, dados esse que podem sugerir que esta população esteja, inserida no mercado de trabalho, cabendo ressaltar que o dado não foi obtido de forma objetiva e que essa população pode inclusive ter renda provinda da prostituição (LERRI, ROMÃO, et al., 2017).

Aproximadamente $20 \%$ da nossa população com idade média de 19 anos está inserida no sistema educacional. A literatura sugere que a escola é um ambiente hostil à população transexual, havendo diversos relatos de preconceito, violência e abuso, o que torna restrito o acesso à educação o que torna ainda maior, a marginalização desta população (ZIOTTI e SANTOS, 2018). A necessidade de programas de educação sexual e melhor prepara dos educadores é essencial para a inserção deste grupo na educação (SILVA e MEGID NETO, 2006), assim como adequar questões sociais. O uso de nome social, vestimentas e acesso a banheiros próprios do gênero vivenciado a esses alunos podem reduzir possíveis casos de violência e discriminação (GUSS, SHUMER e KATZWISE, 2015). Em nossa amostra, os homes trans estão mais inseridos em atividades escolares em relação às mulheres trans, o que pode estar relacionado a melhor aceitação deste grupo no meio social. Sabe-se que homens trans aparentam ter maior qualidade de vida do que mulheres trans, inclusive na questão educacional, embora a qualidade de vida seja inferior à da população não-trans nos dois grupos (VALASHANY e JANGHORBANI, 2018).

$\mathrm{Na}$ nossa avaliação, somente o grupo de mulheres trans estava inserido na prostituição e apresentou positividade para HIV e outras ISTs. A prevalência encontrada de HIV na nossa amostra foi de 17,6\% nas mulheres trans. Sabe-se que a chance de infecção pelo HIV entre transexuais é cinco vezes maior do na população geral (INSTITUTE OF MEDICINE, 2011), chegando a 25\% em alguns centros (COSTA, FONTANARI, et al., 2015 ). Recentemente, um estudo brasileiro encontrou uma prevalência de HIV na população de homens que fazem sexo com homens é de 18,4\%, muito parecido com o valor encontrado na nossa amostra de mulheres trans (KERR, KENDALL, et al., 2018).

Com relação a uso de substâncias, existem poucos dados na literatura sobre tabagismo, etilismo e drogadição, exclusivamente na população trans. A maioria dos estudos contempla avaliação das minorias de gênero (HOFFMAN, DELAHANTY, et al., 2018). Um estudo transversal americano coletado em 2013 que avaliou o uso de tabaco em pessoas cis e pessoas trans concluiu que o uso de tabaco em pessoas trans é maior do 
que em pessoas cis, esse foi o primeiro estudo de prevalência sobre esse assunto a nível nacional nesta população (BUCHTING, EMORY, et al., 2017). Na nossa amostra, um terço de homens e mulheres trans declarou fazer uso do tabaco sendo esta prevalência maior do que a da população brasileira (14,7\%) (IBGE, 2014). O tabagismo é um fator de risco importante para tromboses e deve ser investigado na prescrição do tratamento hormonal, sobretudo nas mulheres trans, que deverão evitar a via oral pelo aumento de risco cardiovascular (HEMBREE, 2017).

De acordo com a OMS, o consumo abusivo de bebidas alcoólicas é considerado um fator de risco para as principais doenças crônicas não transmissíveis, bem como dos acidentes e violência (IBGE, 2014). A prevalência de etilismo referido na nossa amostra foi de $18,1 \%$, sem diferença entre homens e mulheres trans. Segundo o IBGE, em 2013, o percentual da população brasileira que costumava consumir bebida alcoólica uma ou mais vezes por semana era de $24,0 \%$, sendo $36,3 \%$ entre os homens e $13 \%$ entre as mulheres (IBGE, 2014). Os dados na nossa amostra acabaram, pois, sendo inferiores a prevalência nacional, com exceção do grupo de mulheres: $35 \%$ mais mulheres trans ingerem mais álcool do que as mulheres cis. O uso abusivo do álcool é prevalente entre os travestis: Kerr-Corrêa et al (2017), avaliando 304 travestis, concluíram que trêsquartos fizeram uso de álcool no último ano e que pelo menos metade do grupo realizou uso abusivo. Tal consumo também foi um fator associado ao maior risco de relações sexuais desprotegidas, consumo de drogas e aumento da prevalência do HIV (KERRCORRÊA, PINHEIRO, et al., 2017).

A porcentagem do uso de substâncias ilícitas (maconha, cocaínas, ecstasy) referida foi de $11,9 \%$, sendo $13,6 \%$ em mulheres trans e $11,7 \%$ em homens trans. Segundo Day, a prevalência do consumo de drogas e substâncias psicoativas chega a ser de 2,5 a 4 vezes maior em comparação a população não transexual. Os mais jovens são os mais vulneráveis ao consumo precoce dessas substâncias devido à grande vulnerabilidade emocional e social a que estão expostos e ao maior risco de distúrbio psiquiátrico como ansiedade e depressão (DAY, FISH, et al., 2017). Não existem muitos dados nacionais sobre o consumo de substâncias psicoativas, no entanto, um estudo realizado em Ribeirão Preto com estudantes do oitavo ano do ensino fundamental demonstrou que a prevalência de uso de substâncias foi 6,8\% para maconha; $2,7 \%$ a cocaína; $1,6 \%$ para alucinógenos e 0,3\% para consumo de alguma substância a base de opiáceos (MUZA, BETTIOL, et al., 1997). Uma outra pesquisa realizada em 107 cidades a nível nacional, com pessoas entre 12 e 65 anos de idade, encontrou uma prevalência do uso de maconha de 6,9\% da 
população e 2,3\% de cocaína. Observa-se que a prevalência do uso de substâncias psicoativas registrada referente ao uso de maconha e cocaína parece ser maior na nossa amostra do que na população geral. Conforme já observado nos dados de Day, a maior prevalência pode ser resultado da marginalização social e risco psicológico desta população (DAY, FISH, et al., 2017). A avaliação da nossa amostra apresenta uma limitação importante pois na maioria dos atendimentos não está descrito o tipo de substância que a pessoa faz uso, a frequência ou a quantidade.

Um dado que chama a atenção na nossa amostra é baixa prevalência de ansiedade e depressão referidos. Um estudo europeu, avaliando uma população transexual entre 2007 e 2010, demonstrou que a prevalência de depressão foi de 38\% (HEYLENS, ELAUT, et al., 2014). Com base nos registros médicos, o diagnóstico de depressão foi de 9,8\% entre as pessoas com DI/G atendidas no serviço. Destes, 8,8\% era mulheres trans e 11,8\%, homens trans. Em 2015, neste mesmo ambulatório, um estudo transversal com entrevista semiestruturada, encontrou que mais de $80 \%$ desta população sofre de depressão e ansiedade (LERRI, ROMÃO, et al., 2017). A baixa prevalência de depressão e ansiedade nos registros médicos, no entanto sugere que o cuidado médico, muitas vezes, negligencia a avaliação psicológica e psiquiátrica desta população, podendo subestimar estes diagnósticos. Vale lembrar que, as taxas de ideação/tentativa de suicídio, que derivam das precárias condições de saúde mental, chegam a ser 20 vezes maiores nesta população do que na população geral (BLOSNICH, BROWN, et al., 2013). Desta forma, é importante treinar a equipe a investigar tais queixas, assim como avaliar relação afetiva e suporte emocional que são fatores protetores à depressão neste grupo (LERRI, et al., 2017).

Em relação à terapia hormonal, 56,5\% da nossa população já realizavam uso prévio de hormônios, sobretudo, a população de mulheres trans. A automedicação ocorria sem supervisão de profissionais qualificados, o que poderia acarretar importantes agravos à saúde, uma vez que foi observada a prevalência de patologias que causariam aumento de risco cardiovascular nesta população de 10,3\% da amostra. Existe uma tendência na população transexual à automedicação. $\mathrm{O}$ uso de estrogênio oral utilizado na reposição hormonal no climatério e contraceptivos hormonais em altas doses por mulheres trans assim como uso da testosterona, de maneira ilícita, por homens trans configuram as principais forma de acesso ao tratamento hormonal foram do contexto médico (MINISTÉRIO DA SAÚDE, 2015). A adequação hormonal é crucial para adequação do fenótipo da pessoa com D/IG afim de se adquirir os caracteres do gênero almejado 
(HEMBREE, 2017). Conforme discutido anteriormente nesse trabalho, o uso de estrogênios tem por objetivo o aumento das mamas e do depósito de gordura em região dos quadris e redução dos níveis de testosterona enquanto o uso de testosterona tem o objetivo de aumentar a massa muscular, o clitóris e evidenciar caracteres sexuais secundários como o aumento de pelos e mudança no timbre da voz (HEMBREE, 2017). No entanto, o uso desse hormônios precisa ser acompanhado de equipe capacitada, uma vez que o seu uso indiscriminado pode acarretar efeitos colaterais graves com doenças tromboembólicas, câncer de mama e endométrio, eritrocitose, doença coronariana e cerebrovascular, disfunção hepática e infertilidade transitória (HEMBREE, 2017).

A fase de vida, na qual houve maior relato de percepção da incongruência do gênero, na nossa amostra, foi a infância seguida pela adolescência e menos de $10 \%$ percebeu a incongruência na vida adulta. Os dados sobre a idade da percepção da D/IG são escassos mas, um estudo antigo (BLANCHARD, 1988) evidenciou sentimento de disforia em idade precoce. Os nossos achados, obtidos através da avaliação do ginecologista em um serviço de saúde sexual, corroboram estes achados e agregam para a elaboração de protocolos específicos para o cuidado à saúde integral da pessoa trans. Vale acrescentar que estudos prospectivos evidenciam que somente de 2 a $27 \%$ das crianças que manifestam D/IG mantém o diagnóstico na adolescência e vida adulta. Na maioria das vezes estas crianças serão cisgêneros com orientação homossexual ou bissexual, e quanto mais extrema for a expressão da D/IG na infância, maior a chance de persistência desta condição na vida adulta (WALLIEN e COHEN-KETTENSIS, 2008). Quando a criança chega à adolescência com características persistentes de D/IG será alta a permanência da condição na vida adulta. Um follow-up com 70 adolescentes diagnosticados com D/IG submetidos a supressão hormonal mostrou que todos permaneceram com o mesmo gênero na vida adulta (DE VRIES, STEENSMA, et al., 2010), sugerindo a consolidação da identidade tende a ocorrer antes dessa fase.

Contatou-se também, em nossa amostra, que o grupo de homens trans aparentou maior percepção do comportamento de D/IG na infância do que o grupo de mulheres trans. Em um estudo transversal, Smith (2005) avaliou 187 transexuais e concluiu que homens trans também apresentam percepção da D/IG mais precocemente do que as mulheres trans (SMITH, VAN GOOZEN, et al., 2005). Uma outra avaliação realizada em pacientes transexuais masculinos, identificou uma idade média de percepção da incongruência em média aos 6 anos de idade com desvio padrão de 2 anos, sugerindo uma percepção precoce neste grupo (CUNHA, 2013). 
No presente estudo, não foi encontrado o registro das características que sugerem a presença da D/IG desde a infância entre os nossos usuários. Na maioria das vezes, há relatos de uma predileção por brincadeiras e vestimentas típicas do sexo oposto e poucos registros foram feitos sobre o sentimento da pessoa sobre o seu órgão genital no período da infância. Uma avaliação realizada através do questionário "Gender Identity Disorder in Childhood Scale (GIDICS) " que ainda não foi validado para o português, pode elucidar essas questões (SMITH, VAN GOOZEN, et al., 2005). Trata-se de um questionário de 11 itens, que avaliam o desejo de pertencem ao sexo oposto e preferências por vestimentas, brincadeiras e comportamento do sexo oposto na infância. Acredita-se que, embora as características da condição trans possam estar presentes precocemente, possivelmente ela não causam desconforto nesta fase, podendo postergar a sua percepção (SMITH, VAN GOOZEN, et al., 2005). Lobato defende que a consolidação da identidade de gênero ocorrerá mais tardiamente, na adolescência (LOBATO MI, 2009).

De acordo com o desenvolvimento da criança, entre os 6 e 7 meses, ela é capaz de identificar vozes e faces de acordo com o gênero, embora identifique brincadeiras próprias de cada gênero em torno dos 2 anos de idade (FAUSTO-STERLING, 2012). Por volta de 1 ano, já associam objetos a determinados gêneros e iniciam a sua percepção da identidade de gênero entre os 2 e 3 anos (BONIFACIO e ROSENTHAL, 2015). Sabe-se que a ação da testosterona intrauterina contribui para uma maior predileção por brinquedos e brincadeiras relacionados a movimento, típicas do sexo masculino (CAMPBELL e EATON, 1999).

No Brasil existe uma recomendação de que o tratamento hormonal deva ser proposto apenas a adolescentes com mais de 16 anos (CONSELHO FEDERAL DE MEDICINA, 2019). Tal recomendação é recente, no nosso serviço, o tratamento hormonal era até, a coleta deste estudo, prescrito somente a pacientes com mais de 18 anos e, por isso, cento e cinquenta pessoas com diagnóstico de $\mathrm{D} / \mathrm{IG}$ preencheram critérios para iniciar a medicação.

O objetivo do tratamento hormonal é atingir níveis próximos aos níveis do gênero desejado e adequar caracteres físicos. O resultado fenotípico, por outro lado, resulta de uma complexa interação ente receptores e hormônios, sendo que os níveis hormonais obtidos nem sempre correspondem a resposta fenotípica esperada. O uso de testosterona em homens trans segue o protocolo de hipogonadismo de homens cis (HEMBREE, 2017), no entanto, o tratamento hormonal em mulheres trans é um pouco mais complexo, uma vez que o uso de estrogênios isoladamente muitas vezes não é suficiente para inibir o eixo 
de produção da testosterona (GOOREN, GILTAY e BUNCK, 2008). Uma avaliação realizada no HC de São Paulo encontrou em mulheres trans pré-gonadectomia que o uso de estrogênio equino conjugado (EEC) associado ou não a ciproterona resulta na redução nos níveis de testosterona (CUNHA, S., et al., 2018). Embora este dado possa sugerir que apenas o estrogênio seja determinante na redução dos níveis de testosterona, o trabalho tem um número pequeno de pacientes. Guidelines internacionais consagrados recomendam a prescrição de medicações antiandrogênicas a fim de reduzir as contrações séricas de testosterona e atingir caracteres físicos menos androgênicos (HEMBREE, 2017).

Em nossa amostra, a avaliação hormonal das mulheres trans pós tratamento não evidenciou diferenças nas concentrações séricas de estrogênio no grupo que realizou uso de estrogênio isoladamente e no que realizou o estrogênio associado a tratamento com antiandrogênios, medianas 94,2 pg/ml e 70,3 pg/ml, respectivamente. O mesmo foi observado com os níveis de testosterona cujas medianas pós-tratamento foram 134,5 ng/dl e $129 \mathrm{ng} / \mathrm{dl}$, respectivamente. Apesar disso, foi observado que o quartil superior de testosterona pós-tratamento das mulheres trans que não utilizaram a medicação antiadrogênica foi superior ao das mulheres trans que fizeram o uso, $439 \mathrm{ng} / \mathrm{dl}$ e $272.5 \mathrm{ng} / \mathrm{dl}$, repectivamente. Ao interpretar estes dados é preciso atentar para s limitações no nosso estudo: trata-se de um levantamento retrospectivo com uma população que faz uso de valerato de estradiol (em doses que variaram de 2 a $5 \mathrm{mg} / \mathrm{d}$ ) e estrogênios equinos conjugados e, nem sempre faz uso correto da medicação. Além disso, não é infrequente a associação com anticoncepcionais conjugados a base de etinilestradiol que podem alterar essas concentrações tanto de estrogênio quanto de testosterona (MINISTÉRIO DA SAÚDE, 2015).

O objetivo do tratamento com testosterona é atingir níveis masculinos do androgênio (PELUSI, COSTANTINO, et al., 2014) que, em nosso serviço, possui valor de referência entre 250 a $900 \mathrm{ng} / \mathrm{dl}$. A mediana pós-tratamento dos homens trans atendidos no ambulatório foi de $400 \mathrm{pg} / \mathrm{ml}$. As coletas do ambulatório acontecem no nadir da medicação, geralmente 10 dias antes da aplicação da nova ampola de testosterona. Foi observado, infelizmente, uma grande amplitude nas concentrações de testosterona após o início do tratamento hormonal, e, infelizmente, não foi possível justificar as razões para tal. Sabe-se que os homens trans têm uma dificuldade de acesso a testosterona. Frequentemente, há falta dessas formulações em farmácias e uso ilegal através do mercado esportivo (MINISTÉRIO DA SAÚDE, 2015). 
Um dado interessante neste grupo foi a avaliação das concentrações séricas de testosterona pré-tratamento em homens trans virgens de tratamento não gonadectomizados. Dos 48 homens trans virgens de tratamento, 25 tinham dosagens prétratamento e, destes, mais da metade apresentavam níveis hormonais pré-tratamento acima dos valores considerados normais para mulheres cis. A literatura considera em mulheres que não possuem patologias virilizantes ou com hiperandrogenismo, apresentam um percentil 95 para o nível sérico de testosterona variando entre 1.8 a 2.2 $\mathrm{nmol} / \mathrm{ml}$ (CLARK, WALD, et al., 2018), o equivalente a 51.9 a $63.4 \mathrm{ng} / \mathrm{dl}$ (TIETZ, 2007). De forma semelhante, um estudo japonês com 69 homens trans encontrou hiperandrogemia em 39,1\% da amostra e uma prevalência de 58\% de diagnóstico de síndrome dos ovários policísticos em homens trans que não haviam sido submetidos a terapia hormonal ou cirurgia (BABA, ENDO, et al., April 2007).

Esse dado pode reforçar a teoria neuroendócrina da influência do aumento da testosterona em homens trans e a resposta neuronal do comportamento (CLARKSON \& HARLEY, 2002; COLLADO, et al., 1998; GUILLAMÓN, et al., 1998). 


\section{CONCLUSÃO}

Com base nos resultados obtidos, conclui-se que a fase de vida em que ocorre a percepção da D/IG é a infância, fato de maior expressão em homens trans (entre os X e $\mathrm{X}$ anos). Fatores que ocasionem a maior percepção nessa fase, sobretudo nos homens trans, ainda precisem ser melhores estudados.

Existe maior prevalência de HIV, ISTs e prostituição em mulheres trans, enquanto homens trans têm maior inserção em ambientes escolares. É alta a prevalência de tabagismo, consumo de álcool e drogas também em mulheres trans.

Metade dos homens trans virgens de tratamento hormonal apresenta concentração de testosterona sérica total acima do nível superior de corte para mulheres cis.

A automedicação é maior entre as mulheres trans. 


\section{PERSPECTIVAS FUTURAS}

A aplicação de questionários específicos e validados em língua portuguesa que investiguem melhor o comportamento sexual nas diferentes fases da vida pode elucidar as questões de percepção. A validação de instrumento como o "Gender Identity Disorder in Childhood Scale (GIDICS)" é uma sugestão de próximos passos nessa linha de pesquisa.

Quanto as avalições hormonais, os resultados poderão ser melhor elaborados com o desenho de um estudo prospectivo, avaliando dose em tempo específicos e resposta objetiva através de escalas de adequação fenotípica, afim de se identificar doses terapêuticas e seguras para essa população e não basear as prescrições, simplesmente, no modelo do hipogonadismo como hoje ainda é realizado. 


\section{REFERÊNCIAS}

ARCELUS, J.; BOUMAN, W. P.; VAN DEN NOORTGATE, W. E. A. Systematic review and meta-analysis of prevalence studies in transsexualism. European Psychiatry, p. 30(6):807-15, 2015.

BABA, T. et al. Association between polycystic ovary syndrome and female-tomale transsexuality. Human Reproduction, v. 22, n. 4, p. 1011-1016, April 2007.

BAKKER, J. et al. Alpha-fetoprotein protects the developing female mouse brain from masculinization and defeminization by estrogens. Nat Neurosci, n. Feb;9(2), p. 220-6, 2006.

BENJAMIN, H. The Transsexual Phenomenon. New York: Symposium Publishing. 1966.

BENTO, B. A reinvenção do corpo: sexualidade e gênero na experiência transexual. Rio de Janeiro: Garamond, 2006.

BENTO, B. Sexualidade e experiências trans: do hospital à alcova. Cien Saude Colet, v. 17, n. 10, p. 2655-2664, 2012.

BENTZ, E. et al. A polymorphism of the CYP17 gene related to sex steroid metabolism is associated with female-to-male but not male-to-female transsexualism. Fertil Steril., v. Jul; 90(1). Sep 4, p. 56-9. , 2008.

BERENBAUM, A. S.; HINES, M. Early Androgens are related to chidhood sextyped toy preference. Psycological Science., p. v. 3, i. 3, 203- 206, 1992.

BLANCHARD, R. Nonhomosexual gender dysphoria. Journal of Sex Research, v. 24, p. 188-193, 1988.

BLOSNICH, J. et al. Prevalence of gender identity disorder and suicide risk among transgender veterans utilizing veterans health administration care. Am J Public Health, v. 103(10), Oct, p. e27-32, 2013.

BLOSNICH, J. et al. Differences in Alcohol Use and Alcohol-Related Health Care Among Transgender and Nontransgender Adults: Findings From the 2014 Behavioral 
Risk Factor Surveillance System. J Stud Alcohol Drugs, n. Nov; 78(6), p. 861-866., 2017.

BONIFACIO, H. J.; ROSENTHAL, S. M. Gender Variance and Dysphoria in Children and Adolescents. Pediatr Clin North Am., v. 62, n. 4, p. 1001-16, 2015.

BRASIL. MINISTÉRIO DA SAÚDE. Política Nacional de Saúde Integral de Lésbicas, Gays, Bissexuais, Travestis e Transexuais. Brasília: Ministério da Saúde., 2013.

BUCHTING, F. O. et al. Transgender Use of Cigarettes, Cigars, and E-Cigarettes. American Journal of Preventive Medicine, v. 53, n. 1, p. e1-e7, 2017.

CAMPBELL, D. W.; EATON, W. O. Sex differences in the activity level of infants. Infant and Child Development, p. v. 8, i. 1, 1-17, 1999.

CID-11. Coding Desease and Death. ICD-11: Classifying disease to map the way we live and die, 2018.

CLARK, R. V. et al. Large divergence in testosterone concentrations between men and women: Frame of reference for elite athletes in sex-specific competition in sports, a narrative review. Clinical Endocrinology, p. 15-22, 2018.

CLARKSON, M. J.; HARLEY, V. R. Sex with two SOX on. SRY and SOX9 in testis development. Trends Endocrinol Metabolism, n. 13, p. 106-111, 2002.

COLLADO, P.; SEGOVIA, S.; GUILLAMÓN, A. Development of sex differences in the bed nucleus of the accessory olfactory tract in the rat. Developmental Brain Research, v. 109, p. 99-108, 1998.

\section{CONSELHO FEDERAL DE MEDICINA. RESOLUÇÃO CFM nº 2.265/2019.} Rio de Janeiro. 2019.

COSTA, A. B. et al. Population-based HIV prevalence and associated factors in male-to-female transsexuals from Southern Brazil. Arch Sex Behav, v. 44(20), n. Feb, p. 521-4, 2015. 
COULTER, R. et al. The Effects of Gender- and Sexuality-Based Harassment on Lesbian, Gay, Bisexual, and Transgender Substance Use Disparities. J Adolesc Health, v. 62(6), n. Jun, p. 688-700, 2018.

CUNHA, F. S. . E. A. Tratamento de pacientes transexuais masculinos com baixas doses de estrogênio é efetivo para manter os níveis séricos de estradiol e testosterona dentro dos limites de normalidade para o sexo feminino. Arq. Bras. Endocrinol. Metab, São Paulo, 2013.

CUNHA, F. S. et al. Low estrogen doses normalize testosterone and estradiol levels to the female range in transgender women. Clinics , p. e73:e86, 2018.

CUNHA, T. Transexuais são excluídos do mercado de trabalho. Correio Brasiliense, 2017. Disponivel em:

$<$ http://especiais.correiobraziliense.com.br/transexuais-sao-excluidos-do-mercado-detrabalho>. Acesso em: 2019 out. 22.

DAY, J. et al. Transgender Youth Substance Use Disparities: Results From a Population-Based Sample. J Adolesc Health. , n. Dec;61(6), p. 729-735, 2017.

DE CUYPERE, G.; T’SJOEN, G.; BEERTEN, R. E. A. Sexual and physical health after sex reassignment surgery. Archives of Sexual Behavior, v. v. 34, p. 679-690, 2005.

DE VRIES, A. L. C. et al. Puberty suppression in adolescents with gender identity disorder: A prospective follow-up study. The Journal of Sexual Medicine, Advance online publication, 2010.

DEACON, R.; MOONEY-SOMERS, J. Smoking prevalence among lesbian, bisexual and queer women in Sydney remains high: Analysis of trends and correlates. Drug Alcohol Rev. , n. Jul;36(4), p. 546-554, 2017.

DEFREYNE, J.; MOTMANS, J.; T'SJOEN, G. Healthcare costs and quality of life outcomes following gender affirming surgery in trans men: a review. Expert Review of Pharmacoeconomics \& Outcomes Research , v. 17, n. 6, p. 543-556, 2017. 
DELEMARRE-VAN DEN WALL, H. A.; COHEN-KETTENIS, P. Clinical manangemeant of gender identity disorder in adolescents: a protocol on psychological and paediatric endocrinology aspects. European Journal of Endocrinology, v. 155, S131-S137, 2006.

DESSENS, A. B.; SLIJPER, F. M. E.; DROP, S. L. S. Gender dysphoria and gender change in chromossomal females with congenital and adrenal hyperplasia. Archivers of Sexual Behavior, v. 34, i. 4, p. 34(4):389-397, 2005.

\section{DSM-V. Manual Diagnóstico e Estatítisco de Transtorno Mental - DSM-5.} Porto Alegre: Artmed, 2014.

ECKER, J.; , A. T.; SYLVESTRE, J. A Review of the Literature on LGBTQ Adults Who Experience Homelessness. J Homosex, n. Dec 5, p. 1-27, 2017.

EMORY, K. et al. Lesbian, gay, bisexual and transgender (LGBT) view it differently than non-LGBT: Exposure to tobacco-related couponing, e-cigarette advertisements, and anti-tobacco messages on social and traditional media. Nicotine Tob Res, n. Mar 12, 2018.

FAUSTO-STERLING, A. The dynamic development of gender variability. J Homosexuality, v. 59, n. 3, p. 398-421, 2012.

FERNÁNDEZ, R. et al. The (CA)n polymorphism of ER $\beta$ gene is associated with FtM transsexualism. J. Sex. Med., v. 11, p. 720-728, 2014.

FERNÁNDEZ, R. et al. Molecular basis of Gender Dysphoria: androgen and estrogen receptor interaction. Psychoneuroendocrinology., n. Dec (98), p. 161-167, 2018.

FERNÁNDEZ, R. et al. Molecular basis of Gender Dysphoria: androgen andestrogen receptor interaction. Psychoneuroendocrinology, v. 98, p. 161-167, 2018.

GARCIA, L. P.; FREITAS, L. R. S. Consumo abusivo de álcool no Brasil: resultados da Pesquisa Nacional de Saúde 2013. Epidemiologia e Serviços de Saúde, v. 24, n. 2, p. 227-237., 2015. 
GILBERT, P. et al. Alcohol research with transgender populations: A systematic review and recommendations to strengthen future studies. Drug Alcohol Depend, n. May (1); p. 186:138-146., 2018.

GOOREN, L. J.; GILTAY, E. J.; BUNCK, M. C. Long-term treatment of transsexuals with cross-sex hormones: extensive personal experience. J Clin Endocrinol Metab, v. 93(1), p. 19-25, 2008.

GRINSZTEJN, B. et al. Unveiling of HIV dynamics among transgender women: a respondent-driven sampling study in Rio de Janeiro, Brazil. Lancet HIV, v. Apr, n. 4(4), p. e169-e176, 2017.

GUILLAMÓN, A.; SEGOVIA, S.; DEL ABRIL, A. Early effects of gonadal steroids on the neuron number in the medial posterior region and the lateral division of the bed nucleus of the stria terminalis in the rat. Developmental Brain Research, v. 44, i. 2, p. 281-90, 1998.

GUSS, C.; SHUMER, D.; KATZ-WISE, S. L. Transgender and Gender Nonconforming Adolescent Care: Psychosocial and Medical Considerations. Curr Opin Pediatr, v. 26(4), n. Aug, p. 421-426, 2015.

HAGE, J. J. et al. Sculpturing theglans in phalloplasty. Plast Reconstr Surg. , v. 92, n. 1, p. 157-161,discussion 162, 1993.

HARE, L. et al. Androgen receptor repeat length polymorphism associated with male-to-female transsexualism. Biol. Psychiatry, v. 65, p. 93-96, 2009.

HEMBREE, E. A. Endocrine Treatment of Gender-Dysphoric/Gender-Incongruent Persons: An Endocrine Society Clinical Practice Guideline. Journal of Clinical Endocrinology \& Metabolism, p. v. 102, i. 11, 102(11):3869-3903, 2017.

HENNINGSSON, S. et al. ex steroid-related genes and male-to-female transsexualism.. Psychoneuroendocrinology, v. 30, p. 657-664, 2005.

HEYLENS, G. et al. Gender identity disorder in twins: A review of the case report literature. Journal of Sexual Medicine, p. v. 9, i. 3, 751-757, 2012. 
HEYLENS, G. et al. Psychiatric characteristics in transsexual individuals: multicentre study in four European countries. Br J Psychiatry, v. Feb, n. 204 (2), p. 151-156, 2014.

HOFFMAN, L. et al. Sexual and gender minority cigarette smoking disparities: An analysis of 2016 Behavioral Risk Factor Surveillance System data. Prev Med, v. 113, n. Aug, p. 109-115, 2018.

IBGE. Pesquisa Nacional de Saúde 2013. Rio de Janeiro, 2014.

INSTITUTE OF MEDICINE. The Health of Lesbian, Gay, Bisexual, and Transgender People: Building a Foundation for Better Understanding. Washington, DC. 2011.

JAMAL, A. et al. Current cigarette smoking among adults-United States, 20052015. MMWR Morb. Mortal. Wkly. Rep., v. 65, p. 1205-1211, 2016.

KERR, L. et al. HIV prevalence among men who have sex with men in Brazil: results of the 2nd national survey using respondent-driven sampling. Medicine (Baltimore), v. May, n. 97(1S Suppl 1), p. S9-S15, 2018.

KERR, L. et al. HIV prevalence among men who have sex with men in Brazil: results of the 2nd national survey using respondent-driven sampling. Medicine (Baltimore), v. 97, n. 1S Suppl 1, p. S9-S15, 2018.

KERR-CORRÊA, F. et al. Hazardous alcohol use among transwomen in a Brazilian city. Cad Saude Publica, v. Apr 3, p. 33(3), 2017.

KOHLBERG, L. A. A cognitive-developmental analysis of children's sex role concepts and attitudes. In: PRESS, S. U. The Development of Sex Differences. Stanford, CA: Maccoby, E.E. (Ed.), v. 3, 1996. p. 82-173.

KREUKELS, B. P. C.; COHEN-KETTENIS, P. Puberty suppression in gender identity disorder: the Amsterdam experience. Nature Reviews Endocrinology, p. v. 7, 7:466-72, 2011.

KROGER, J. Gender and Identity: The Intersection of Structure, Content, and Context. Sex Roles, v. 36, n. 11/12, p. 747-770, 1997. 
KUDWA, A. E. et al. Roles of Estrogen receptors alpha and beta in differentiation of mouse sexual behavior. Neuroscience, v. 138, p. 921-928, 2006.

LANDÉN, M.; WALINDER, B.; LUNDSTRÖM, B. Prevalence, incidence and sex ratio of transsexualism in Sweden. Acta Psychiatrica Scandinavica, p. 93:261-3, 1996.

LEE, P. A. et al. Consensus statement on management of intersex disorders. International Consensus Conference on Intersex. Pediatrics, v. 118(2), n. 8, p. e488$500,2006$.

LEIBOWITZ, S.; SPACK, N. The development of a gender identity psychosocial clinic: treatment issues, logistical considerations, interdisciplinary cooperation, and future initiatives. Child Adolesc Psychiatr Clin N Am, v. 20(4), n. Oct, p. 701-724, 2011.

LERRI, M. R. et al. Clinical Characteristics in a Sample of Transsexual People. Revista Brasileira De Ginecologia E Obstetrícia, v. v. 39, p. 39:373-440., 2017.

LOBATO MI, K. W. C. T. C. C. S. J. P. A. E. A. Using the Defensive Style Questionnare to evaluate the impact of sex reassigment surgery on defensive mechanisms in transsexual patients. Revista Brasileira de Psiquiatria, v. 31, n. 4, p. 303-6, 2009.

MCCARTHY, M. Estradiol and the Developing Brain. Physiological Reviews, Physiological Reviews, p. 91-134, 2008.

MEYER-BAHLBURG, H. F. L. et al. Prenatal androgenization affects genderrelated behavour but not gender identity in 5-12 year old girls with congenital adrenal hyperplasia. Archivers of Sexual Behavior, v. 33, 22(2):97-104, 2004.

MEYER-BAHLBURG, H. F. L.; DROP, S. L. S. Gender Dysphoria and Gender change in cromosomal of sex development. Hormone and Metabolic Research, p. 47(5):361-366., 2015.

MINISTÉRIO DA SAÚDE. PREVENÇÃO CLÍNICA DE DOENÇA CARDIOVASCULAR, CEREBROVASCULAR E RENAL CRÔNICA - Cadernos de Atenção Básica n. ${ }^{\circ}$ 14. Brasília - DF, 2006. 
MINISTÉRIO DA SAÚDE. Portaria 2836, de 1 de Dezembro de 2011. Acesso em: 31/07/2018. Ministério da Saúde, 2011. Disponivel em:

<http://bvsms.saude.gov.br/bvs/saudelegis/gm/2011/prt2836_01_12_2011.html>.

MINISTÉRIO DA SAÚDE. Aids no Brasil: epidemia concentrada e estabilizada em populações de maior vulnerabilidade. Boletim Epidemiológico da Secretaria de Vigilância em Saúde, p. v. 43, 2012.

MINISTÉRIO DA SAÚDE. Portaria 571, de 5 de Abril de 2013., 2013. Disponivel em: <http://portalarquivos2.saude.gov.br/images/pdf/2014/maio/12/Portaria-571tabagismo.pdf>. Acesso em: 31 jul. 2018.

MINISTÉRIO DA SAÚDE. Transexualidade e Travestilidade na Saúde. Brasilia - DF: Editora MS, 2015.

MINISTÉRIO DA SAÚDE. Ministério da Saúde, 2017. Disponivel em: <http://www.saude.gov.br/noticias/agencia-saude/27125-ministerio-da-saude-habilitanovos-servicos-ambulatoriais-para-processo-transexualizador>. Acesso em: 16 jun. 2019.

MUZA, G. et al. The consumption of psychoactive substances by adolescents in schools in an urban area of Southeastern region of Brazil. I - Prevalence by sex, age and kind of substance. Journal of Public Health, v. 31, n. 1, p. 21-29, 1997.

OLSHAN, J. . E. T. . E. "Gender Incongruity in Children With and Without Disorders of Sexual Differentiation." Endocrinol Metab Clin North Am 45(2), p. 463 $482,2016$.

ONU - NAÇÕES UNIDAS. ONU livres \& iguais. ONU livres \& iguais, 2013. Disponivel em: <https://www.unfe.org/pt-pt/definitions/>. Acesso em: $01 \mathrm{dez} .2019$.

PANG, K. et al. Molecular Karyotyping in Children and Adolescents with Gender Dysphoria. Transgend Health., n. Aug 13(1), p. 147-153, 2018.

PAULY, I. B. The current status of the change of sex operation. Jornal of Nervous and Mental Desease, p. 147(5):460-71, 1968. 
PELUSI, C. et al. Effects of three different testosterone formulations in female-tomale transsexual persons. Journal of Sexual Medicine, v. 11(12), p. 3002-3011, 2014.

PHOENIX, C. H. et al. Organizing action of prenatally administered testosterone propionate on the tissues mediating mating behavior in the female guinea pig. Endocrinology, p. v. 65, i. 3, 369-382., 1959.

PINTO, M. J. C.; BRUNS, M. A. D. T. Vivência Transexual: o corpo desvela seu drama. [S.1.]: Átomo, 2003.

POLLOCK, L.; EYRE, S. L. "Growth into manhood: identity development among female-to-male transgender youth." Cult Health Sex 14(2), p. 209-222., 2012.

RAZNAHAN, A. et al. Longitudinally mapping the influence of sex and androgen signaling on the dynamics of human cortical maturation in adolescence. ProcNatl Acad Sci U S A., v. 107, p. 16988-16993, 2010.

ROSENTHAL, S. M. Approach to the patient: transgender youth: endocrine considerations, Journal of Clinical Endocrinology \& Metabolism, v. v. 99, i. 12, n. 4379-4389, 2014.

ROTH, C. Therapeutic potential of GnRH antagonists in the treatment of precocious puberty. Expert Opinion on Investigational Drugs., 11(9):1253-1259., 2002.

SILVA, R. C. P.; MEGID NETO, J. Background of teachers and educators for approach to sexual education at schools: what research works show. Ciência $\mathbf{E}$ Educação, v. 12, n. 2, p. 185-197, 2006.

SMITH, Y. L. S. et al. Sex reassignment: outcomes and predictors of treatment for adolescent and adult transsexuals. Psychological Medicine, v. 35, p. 89-99, 2005.

SMITH, Y. L. S. et al. Transsexual subtypes: clinical and theoretical significance. Psychiatry research, v. 137, p. 151-160, 2005.

SOWELL, E. R. et al. Sex differences in cortical thickness mapped in 176 healthy individuals between 7 and 87 years of age. Cerebral Cortex, p. v17, i. 7, 1550-1560, 2007. 
SPIZZIRRI, G. et al. Grey and white matter volumes either in treatment-naive or hornome-treated transgender women: a voxel-based morphometry study. Scientific Reports, p. v8, 8:736, 2018.

SRASWAT, A.; WEINDAND, J. D.; SAFER, J. Evidence supporting the biologic nature of gender identity. Endocrine Practice, v. 21, n. 2, p. 199-204, 2015.

STEENSMA, D. S. et al. Desisting and persisting gender dysphoria after childhood: a quantitative follow-up, v. 16, n. 4, p. 499-516, 2010.

STOLLER, R. A experiência transexual. Rio de Janeiro: Imago, 1982.

SWIFT-GALLANT, A.; MONKS, D. A. Androgenic mechanisms of sexual differentiation of the nervous system and behavior.. Front. Neuroendocrinol. , v. 46, p. $32-45,2017$.

THOMPSON \& THOMPSON. Genética Médica. 7a. Edição. ed. Elsevier Editora Ltda, 2007.

TIETZ, N. W. Fundamentals of Clinical Chemistry. Philadelphia, PA : 6th Edition, , 2007.

UJIKE, H. et al. ssociation study of gender identity disorder and sex hormonerelated genes. Prog. Neuropsychopharmacol. Biol., v. 33, p. 1241-1244, 2009.

UNITSLAB.COM , 2019. Disponivel em: <http://unitslab.com/node/136>. Acesso em: 16 out. 2019.

VALASHANY, B. T.; JANGHORBANI, M. Quality of life of men and women with gender identity disorder. Health Qual Life Outcomes, v. Aug , n. 20, p. 1-9, 2018.

WALLEN, K. Hormonal influences on sexually differentiated behavior in nonhuman primates. Frontiers in Neuroendocrinology, v. 26, n. 1, p. 7-26, 2005.

WALLIEN, M. S. C.; COHEN-KETTENIS, P. Psychossexual outcome of genderdysphoric children. Journal of the American Academy of Child \& Adolescent Psychiatry, v. 47, i. 12, p.1413-23, 2008. 
WALLIEN, M. S. C.; COHEN-KETTENSIS, P. T. Psychosexual outcome of gender-dysphoric children. Jornal of the American Academy of Child and Adolescent Psychiatry, v. 47, p. 1413-1423, 2008.

WHO. Young People's Health - a Challenge for Society Report of a WHO Study Group on Young People and "Health for All by the Year 2000". Genebra, 1986.

WORLD PROFESSIONAL ASSOCIATION FOR TRANSGENDER HEALTH, INC. Standards of Care for the Health of Transsexual, Transgender, and GenderNonconforming People, n. 7, 2012.

ZIOTTI, M. C.; SANTOS, M. A. Capítulo 7: o contexto do aluno transexual. In: Qualidade e Políticas Públicas na Educação 2. Ponta Grossa (PR): Atena Editora, 2018. p. 73-80. 
ANEXO A: Parecer consubstanciado do CEP

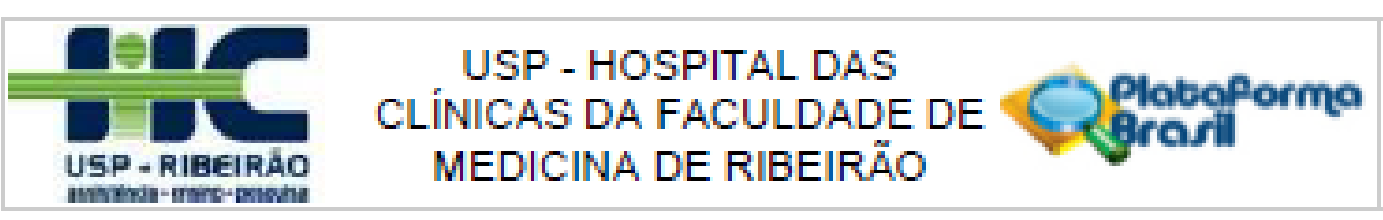

PARECER CONSUBSTANCIADO DO CEP

\section{DADOS DO PROJETO DE PESQUISA}

Titulo da Pesqulsa: Caracteristicas clinicas e soclodemograflcas de uma populaçăo com Disforla/Incongruencla de Genero

Pesqulsador: SERGIO HENRIQUE PIRES OKANO

Área Tematlica:

Versas: 3

CAAE: 94406518.0 .0000 .5440

Institulçă Proponente:UNIVERSIDADE DE SAO PAULO

Patrocinador Principal: Financlamento Proprio

DADOS DO PARECER

Numero do Parecer: 2.869.106

Apresentaça do Projeto:

Estudo retrospectivo com levantamento dos dados medlante revisalo de prontuarios de pessoas com dlagnostico de D/G em segulmento no Ambulatorio de Estudos em Sexualdade Humana (AESH) da Faculdade de Mediclna de RIbelrăo Preto da USP a partir de Janeiro de 2010. O AESH tem uma periodicldade semanal, as segundas-felras pela manhă e as terças-ferias pela tarde e atende aproximadamente 15 pessoas com Incongruencla de genero semanaimente. A equipe de culdado e composta por ginecologistas, psiqulatra, psicologo, fonoaudlologo que trabalha em um modelo Interdlsciplinar oferecendo o processo transexualzador parclal: avalaçăo clinica, psiquatrica e psicologica, hormonioterapla e adequaçăo da voz sendo 05 casos cirürgicos encaminhados para outro serviço.

\section{Objettivo da Pesquisa:}

Verificar o periodo da vida em que as pessoas com UDG perceberam a Incongruencla com o genero que Ines fol designado ao nascimento

\section{Avallaç:so dos Riscos $\theta$ Beneficlos:}

Considerando que o estudo sera conduzido atraves de analise de Informaçoles ootidas em prontuarios, para evitar 0 risco de perda de confidencialidade dos dados, 06 autores codificaram os dados de identifcaçăo e 05 mantlveram 500 sigllo dos pesqulsadores. Por outro lado, a determinaçắo da prevalencla de comorbidades e fatores de risco assoclados a essa populaçăo,

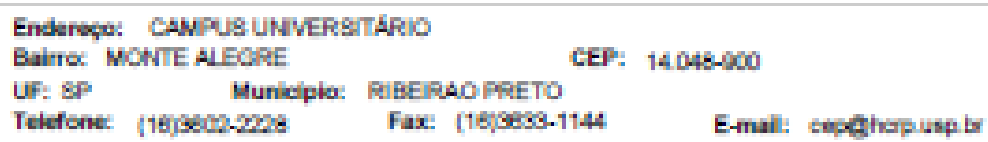




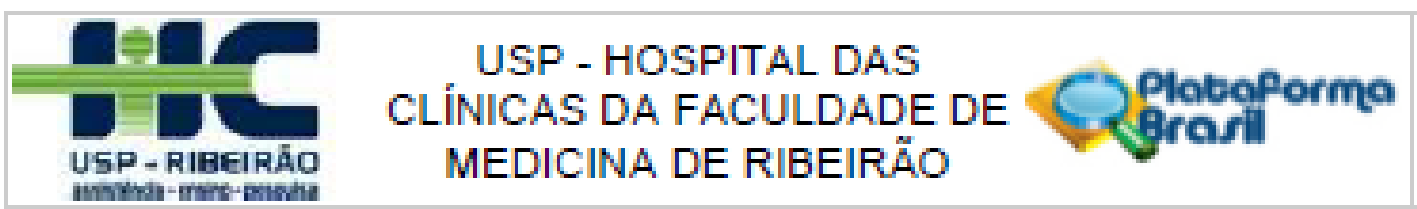

Corthusk do Pawcer 2 ane soe

bem como Identificar momento de reconhecimento da DIG nesta populaçấ, podem mehorar as politicas assistencialstas a este grupo, alem de proporcionar embasamento dentinco para definlçăo e consoldaçăo dos protocolos cilinicos assistencials a serem adotados.

\section{Comentarlos $\theta$ Consideraç0es sobre a Pesqulsa:}

Trata-se de encaminhamento das respostas referentes as recomendaçbes da CONEP, conforme parecer 2.790.419:

1. "Sollcta-se retirar a indlcaçăo de que se trata de pesquisa da area tematica "Genetica Humana: (Havera envio para o exterior de material genetco ou qualquer materlal bioiogico humano para obtenç5o de material genetco, salvo nos casos em que houver cooperaçăo com o Govemo Brasleiro)" no cadistro do protocolo de pesquisa na Plataforma Brasll, uma vez que esse estudo năo se enquadra na area tematica selecionada (Resoluçăo CNS n 466 de 2012, item IX.4) e Carta Circular n० 172/2017/CONEPICNSIMS."

Corforme sollctiado, fol realizada a alteraçäo no cadastro.

2. "Quanto ao projeto detalhado referente ao arqulvo "projetocomigldo.docx": na pagina 6 de 9 le-se: "seraelaborado um banco de dados contendo a ldade, pronssăo, presença de comorbldades (doenças cronicas endocinas, cardiovasculares, Irfeciosas), habitos (tumo, etllismo e drogas licilas), terapla hormonal previa, periodo da vida em que percebeu a incongruencla, medicaçăo proposta e medicaçăo em uso.: Sollitam-se malores esclarecimentos sobre o local e funcionamento desse banco de dados, bem como: Informaçbిes referentes aos mecanismos que serăo adotados para garantir a confidenclalldade $e$ a segurança das Informaçøes contidas nos bancos de dados.

2.2. As varlavels dos bancos de dados que serăo utilizadas. 2.3. A aprovaçăo do gestor (pesquisador responsavellinstitulçăo proponente) responsavel pelo banco de

dados para o compartilhamento das Informaçbes. 2.4. Termo de Compromisso de utilizaçăo de Dados (TCUD) assinado pelos pesquisadores."

O paragrafo fol reescrito, NÄO sera utilzado um banco de dados, os dados referentes as varlavels que serd̆o avalladas (idade, pronssalo, comortidades, habitos, terapla hormonal prevla, periodo de vida em que se percebeu a incongruencla, medlcaça proposta e medlcaçbes) serăo tabulados para analise estatistica. Envado junto a as correçes do projeto encontra-se o TCUD.

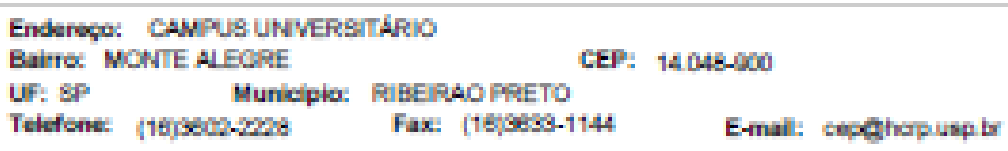




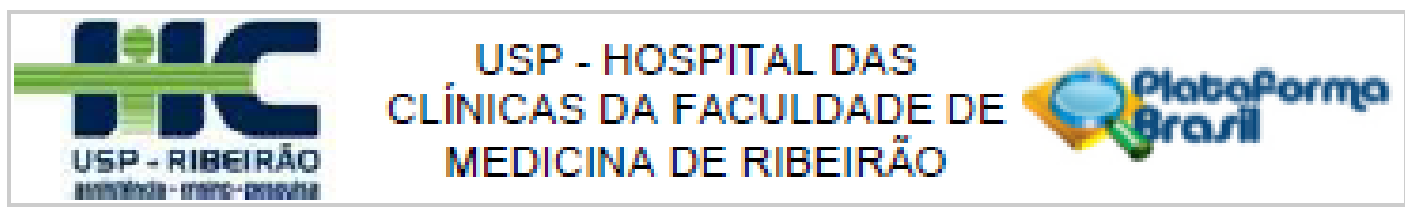

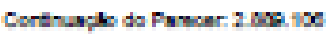

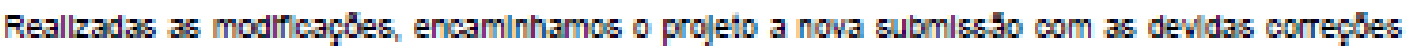
realçadas em vermelho e com a data de 12/09/2018.

Consideraç0es sobre 08 Termos de apresentaçao obrigatorla:

Documentos devidamente apresentados.

Recomendaç0e8:

năo se aplica

Conclus06e ou Pendênclas $\theta$ Llata de inadequaçes:

O CEP considera que 06 pesquisadores atenderam adequadamente as recomendaçbes sollicitadas no Parecer CONEP.

Consideraços Finals a criterio do CEP:

Projeto Aprovadoc Tendo em vista a legislaçăo wgente, deven ser encaminhados ao CEP, relatorlos parclals anuais referentes ao andamento da pesquisa e relatorio final ao termino do trabalho. Qualquer modificaçato do projeto original deve ser apresentada a este CEP em nova versfo, de forma objetiva e com Justificativas, para nova apreclaçăo.

Este parecer fol elaborado bsesado nos documentos abalxo relacionados:

\begin{tabular}{|c|c|c|c|c|}
\hline Tipo Documento & Arquilvo & Postagem & Autor & Situaça \\
\hline $\begin{array}{l}\text { Informaç,es Basicas } \\
\text { do Proleto }\end{array}$ & $\begin{array}{l}\text { PE_INFOFWAÇOES_EASICAS_DO_P } \\
\text { ROUETO } 1173736 . p \bar{d}\end{array}$ & $\begin{array}{c}11,09 / 2018 \\
22: 51: 09\end{array}$ & & ACEto \\
\hline Outros & RESPOSTA_CEP2.docx & $\begin{array}{c}11 / 09 / 2018 \\
22: 49: 34\end{array}$ & $\begin{array}{l}\text { SERGIO HENRICUE } \\
\text { PIRES OKANO }\end{array}$ & Acelto \\
\hline Outros & TCUDpar & $\begin{array}{l}11,0912018 \\
22: 48: 50\end{array}$ & $\begin{array}{l}\text { SERGIO HEVNFICUE } \\
\text { PIRES OKANO }\end{array}$ & ACEto \\
\hline $\begin{array}{l}\text { Projeto Detalhado / } \\
\text { Brochura } \\
\text { Investipador }\end{array}$ & projetoversa02.docx & $\begin{array}{l}31 / 07 / 2018 \\
10: 04: 26\end{array}$ & $\begin{array}{l}\text { SERGIO HENRICUE } \\
\text { PIRES OKANO }\end{array}$ & Acelto \\
\hline Brochura Pesquisa & versa02.docx & $\begin{array}{l}31 / 07 / 2018 \\
10: 03: 46\end{array}$ & $\begin{array}{l}\text { SERGIO HENRIQUE } \\
\text { PIRES OKANO }\end{array}$ & Acelto \\
\hline Outros & RESPOSTA_CEP.dOCX & $\begin{array}{c}30 / 07 / 2018 \\
15: 54: 23\end{array}$ & $\begin{array}{l}\text { SERGIO HENRIQUE } \\
\text { PIRES OKANO }\end{array}$ & Acelto \\
\hline $\begin{array}{l}\text { Projeto Detalhado / } \\
\text { Brochura } \\
\text { Investipador }\end{array}$ & projetocortigldo.docx & $\begin{array}{c}25 / 07 / 2018 \\
19: 23: 56\end{array}$ & $\begin{array}{l}\text { SERGIO HENRIQUE } \\
\text { PIRES OKANO }\end{array}$ & Acelto \\
\hline Brochura Pesqulsa & projeto. $000 x$ & $25 / 07 / 2018$ & SERGIO HENRIQUE & Acelto \\
\hline
\end{tabular}

Endereģo: CANOUS UNVERSTRRRIO

Bairro MONIE ALEORE

CEP: $14046-900$

UF: SP Muricipia: RIBERAO PRETO

Telefone: (16)36ee-2028 Fax: (16)3es3-1144 E-mail: cepahopusply 


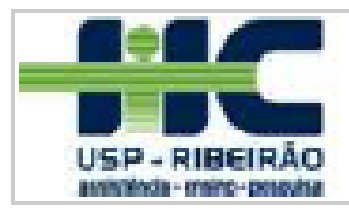

\section{USP - HOSPITAL DAS \\ CLÍNICAS DA FACULDADE DE MEDICINA DE RIBEIRÃO}

Corthusck do Pawer 2 ove ice

\begin{tabular}{|c|c|c|c|c|}
\hline Brochura Pesquisa & projeto.docx & $19: 23: 20$ & PIRES OKANO & Acelto \\
\hline $\begin{array}{l}\text { TCLE / Termos de } \\
\text { Assentimento / } \\
\text { Justilicativa de } \\
\text { Ausencla }\end{array}$ & tcle.pdf & $\begin{array}{c}25 / 07 / 2018 \\
13: 03: 48\end{array}$ & $\begin{array}{l}\text { SERGIO HENRIQUE } \\
\text { PIRES OKANO }\end{array}$ & Accito \\
\hline Folha de Rosto & folhaderosto.pdf & $\begin{array}{c}25 / 07 / 2018 \\
10: 37: 23\end{array}$ & $\begin{array}{l}\text { SERGIO HENRIQUE } \\
\text { PIRES OKANO }\end{array}$ & Acelto \\
\hline Outros & Lattesserglo.pdt' & $\begin{array}{c}24 / 07 / 2018 \\
10: 42: 51\end{array}$ & $\begin{array}{l}\text { SERGIO HENRIQUE } \\
\text { PIRES OKANO }\end{array}$ & Aceito \\
\hline Outros & Curnaloluca.por & $\begin{array}{c}2407 / 2018 \\
10: 42: 35\end{array}$ & $\begin{array}{l}\text { SERGGIOHEINRICUE } \\
\text { PIRES OKANO }\end{array}$ & Aceto \\
\hline $\begin{array}{l}\text { Declaraç5o de } \\
\text { insttulchato e } \\
\text { intraesinutura }\end{array}$ & upc.jpg & $\begin{array}{c}24 / 07 / 2018 \\
10: 41: 30\end{array}$ & $\begin{array}{l}\text { SERGIO HENRICUE } \\
\text { PIRES OKANO }\end{array}$ & Acelto \\
\hline Orçamento & Orcamento.docx & $\begin{array}{c}24 / 07 / 2018 \\
10: 21: 21\end{array}$ & $\begin{array}{l}\text { SERGIO HENRIQUE } \\
\text { PIRES OKANO }\end{array}$ & Aceito \\
\hline $\begin{array}{l}\text { Declaractáso de } \\
\text { Insttulçato e } \\
\text { Intraestiutura }\end{array}$ & Image.pdt & $\begin{array}{c}24 / 07 / 2018 \\
10: 19: 48\end{array}$ & $\begin{array}{l}\text { SERGIO HENRIQUE } \\
\text { PIRES OKANO }\end{array}$ & Acelto \\
\hline
\end{tabular}

sltuaça do Parecer:

Aprovado

Neceselta Apreclaçă da CONEP:

Nấ

RIBEIRAO PRETO, 12 de Setembro de 2018

Assinado por:

MARCIA GUIMARAES VILANONA

(Coordenador)

Endereco: CANCUS UNVERBTTARIC

Bairre MONTE ALEORE

UF: SP Municipia: RIBERAO PRETO

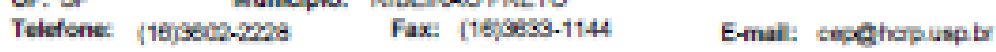


ANEXO B: Aprovação do Projeto pelo Departamento de Ginecologia e Obstetrícia

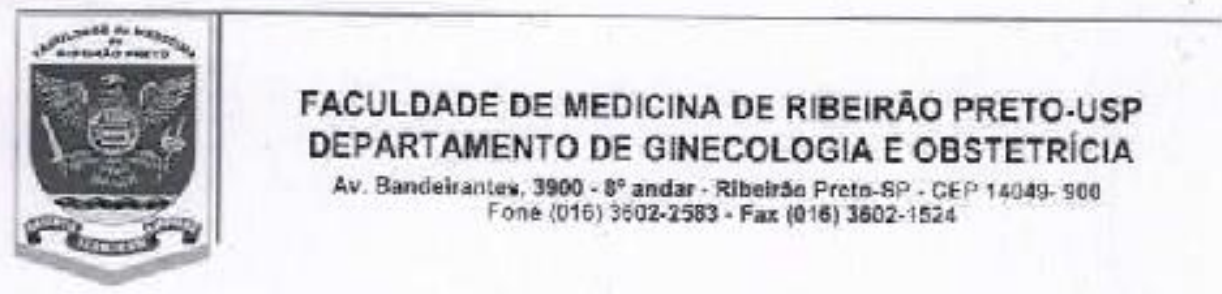

Ribeirâo Prcto, 5 de jultho de 2018.

llma Sra Profa. Dra

Lucia Alves da Silva Lara

Prezada Profossora,

O projeto intitulaco "Estudo rotrospectivo com levantamento dos dados de revisăo de prontuários de pessoas com dlagnóstico de disforiafincongruôncla de gênero em seguimento no Ambulatório de Estudos em Sexualidade Humana (AESH) do Hospital das Clinicas de Ribeirăo Preto da Faculdade de Medicina de Ribeirão Preto da USP", protocelado scb $n^{\sigma} 934$ ce sua autoria foi analisado pela Comissẫo de Pesquisa do Depsrtemento de Ginesologia e Qbstetricia.

Informamos que o projeto fo APROVADO COM SUGESTĀO para ser desenvolvido em nosso Departamento, devendo ser anviado a Comissâo de ṫtica em Pesquisa do Hospital das Clinicas de Ribeirăo Prato para análise, antés do inico da coleta do cados.

Atenciosamente,

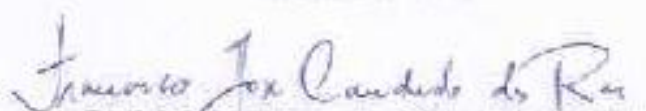

Prof. Dr. Francisea Jase Candido dos Rois

Presidente da Comissta de Pesquisa do Departamento de

Ginecologia e Obstetricia 
ARTIGO: Title: Age at Initial Perception of Gender Incongruence

\begin{abstract}
Introduction: Gender incongruence (GI) is a condition in which a person's gender identity differs from the sex assigned at birth. An initial perception of GI may occur at different ages. GI can lead to significant discomfort and the inability to integrate into society. Objective: To identify the age when individuals first perceive GI, and to compare the sociodemographic characteristics of those who are male-to-female $(\mathrm{MtF})$ and femaleto-male (FtM) in a sample of subjects with GI. Methodology: Cross-sectional study based on a review of the medical records of individuals diagnosed with GI at the Gender Incongruence Clinic of Hospital das Clínicas de Ribeirão Preto (Brazil). Results: 193 individuals with GI, 109 (56.5\%) of whom reported the first perception of GI during childhood. FtMs reported earlier perception of GI than MtFs $(\mathrm{OR}=2.05, \mathrm{p}=0.02)$, and more students were FtMs than MtFs $(\mathrm{OR}=2.15, \mathrm{p}=0.03)$. All subjects who reported engaging in prostitution ( $\mathrm{n}=8$ ), had sexually transmitted infections (STIs; $n=26$ ), and were HIV-positive $(n=22)$ were MtFs. Overall, subjects with GI had high prevalences of smoking (35.9\%), use of alcohol (18.1\%), and use of psychoactive substances (11.9\%). More MtFs than FtMs used hormonal self-medication prior to the first appointment (69.6\% vs. 32.3\%, OR: 4.87, p < 0.01). Conclusion: The initial perception of GI mostly occurs during childhood, and occurs earlier in FtMs than MtFs. MtFs reported more selfmedication with hormones and had higher rates of prostitution, STIs, and HIV infection.
\end{abstract}

Keywords: transsexualism, transgender people, gender dysphoria, sexual and gender minorities 


\section{Introduction}

Gender incongruence (GI), a condition in which a person's gender identity differs from the sex assigned at birth, can cause suffering and the desire to alter the body's appearance (ICD-11, 2018). The prevalence GI has increased in recent years, possibly because of the increased visibility and destigmatization of this condition. A recent study reported that 4.6 people per 100,000 hav (Fernández, et al., 2018)e GI, with about 6.8 males-to-females (MtFs) and 2.6 females-to-males (FtMs) per 100,000 people (Arcelus, Bouman, \& Van den Noortgate, 2015).

The etiology of GI is uncertain; however interactions among biological, environmental, and cultural factors are likely to be important (Rosenthal, 2014). Recent

research suggested that polymorphisms of estrogen and testosterone receptors and of enzymes involved in the metabolism of these hormones have roles in the etiology of GI (Kudwa, Michopoulos, Gatewood, \& Rissman, 2006; Raznahan, et al., 2010; Henningsson, et al., 2005; Fernández, et al., 2018).

Although some studies suggested that hormonal changes can modulate brain connections, even during the intrauterine period (Bakker, 2006; McCarthy, 2008), it is not yet known exactly when an individual first perceives GI. Retrospective studies inferred that the perception of GI had an early onset (Blanchard, 1988), but prospective data suggest that only 2 to $27 \%$ of children diagnosed with GI will maintain these diagnoses in adulthood, and that the presence of GI during adulthood is associated with a stronger expression of GI during childhood (Wallien \& Cohen-Kettensis, 2008).

People with GI have a greater risk for depression and anxiety, and higher rates of suicidal ideation and suicide attempts than those who are cisgender (Lerri, et al., 2017). Many individuals with GI are expelled from their homes during adolescence and then work in prostitution, thus making them more susceptible to sexually transmitted 
infections (STIs) and illicit drug use (Ecker, Aubry, \& Sylvestre, 2017). These individuals are also more likely to have high consumption of tobacco, alcohol, and recreational drugs, which increases their risk of engaging in unprotected sexual relationships and being a victim of violence (Bonifacio \& Rosenthal, 2015)

Researchers therefore consider it essential to alter the physical appearance of an individual with GI to improve the person's quality of life (De Cuypere, T'Sjoen, \& Beerten, 2005). In Brazil, hormone therapy is available to those over 16 years-old (Conselho Federal de Medicina, 2019). This study seeks to identify the age at which an individual first perceives GI and the sociodemographic differences between MtFs and FtMs in a sample of people with GI who received care at the Gender Incongruence Clinic (AING) of the Ribeirão Preto Medical School (USP).

\section{Methodology}

This was a cross-sectional study in which data were obtained by a review of the medical records of all people with GI who had appointments at the USP-AING between January 2010 and July 2018. The medical records of all individuals who had a first appointment at the clinic requesting hormone treatment or hormone treatment with surgery were reviewed. Subjects whose medical records did not contain the minimum data for the proposed analyses were ineligible.

Multiple demographic and clinical factors were analyzed. At the initial visit, age and employment status were recorded on the registration form. The presence of any diseases related to cardiovascular risk (e.g. chronic endocrine and cardiovascular diseases) such as diabetes mellitus, hypertension, coronary artery disease, dyslipidemia, and self-reported or newly identified thrombosis were recorded. The presence of STIs was obtained by directly asking the subject, physical examination, and/or laboratory 
results. Habits such as smoking, drinking, and illicit drug use, were also recorded. The use of hormones prior to first appointment was also recorded

Data regarding the age at which a subject first perceived GI was obtained using the question: "How old were you when you realized you felt like a woman (or man)?" The possible answers were "childhood", "adolescence", or "adulthood". The World Health Organization (WHO) considers childhood as younger than 10 years-old, adolescence as 10 to 19 years-old, and adulthood as more than 19 years-old (WHO, 1986).

\section{Statistical analysis}

Qualitative variables are expressed as absolute and relative frequencies, and quantitative variables as means and standard deviations. The chi-square test and odds ratio were used to compare categorical variables.

\section{Results}

We initially identified 210 individuals who were potentially eligible for inclusion (Figure 1). We excluded 17 individuals because they did not attend their appointments, and ultimately included 193 subjects who attended their appointments and had data that were extractable. One hundred and twenty-five $(64.8 \%)$ of these subjects were MtFs (average age: $27 \pm 9$ years) and the other 68 (35.2\%) were FtMs (average age: $27.2 \pm 9.2$ years)

Further analysis of the age distribution of the study subjects (Table 1) indicated that $17(8.8 \%)$ were younger than 18 years-old (MtF: 11, 8.8\%; FtM: 6, 8.8\%), 129 (66.8\%) were 18 to 29 years-old (MtF: 75, 60.0\%; FtM: 54, 79.4\%), 43 (22.3\%) were 30 to 50 years-old (MtF: 36, 28.8\%; FtM: 7, 10.3\%), and $4(2.1 \%)$ were over 50 years-old (MtF: 3, 2.4\%; FtM: 1, 1.5\%). 
One hundred and twenty-eight subjects (66.3\%) reported that they were working, and $8(4.2 \%)$ of them (all MtFs) reported that their work was exclusively or mostly prostitution. Thirty-six subjects $(18.7 \%)$ were students, and there were significantly more FtM than MtF students (MtF: 18, 14.4\%; FtM: 18, 26.5\%; OR = 2.15, $\mathrm{p}=0.03)$

Fifteen (12\%) MtFs and 5 (7.4\%) FtMs had an underlying medical condition that was associated with an increased risk of cardiovascular disease. Anxiety and depression were self-reported or identified in 19 individuals $(9.8 \%)$ overall (MtF: 11, 8.8\%; FtM: 8, 11.8\%; $\mathrm{p}=0.51)$. STIs were present in 26 subjects $(13.5 \%)$, based on the presence of a clinical lesion or serological results, and all 26 of these subjects were MtFs. HIV was diagnosed in 22 of these subjects (17.6\%). None of the FtMs had an STI and none were HIV-positive.

Analysis of health-related habits indicated that 50 subjects $(35.9 \%)$ were smokers (MtF: 27, 21.6\%; FtM: 23, 33.8\%; p = 0.06), 35 (18.1\%) reported regular alcohol intake (MtF: 22, 17.6\%; FtM: 13, 19.1\%; p = 0.79), and 23 (11.9\%) reported recreational drug use (FtM: 17, 13.6\%; MtF: 8, 11.7\%; $\mathrm{p}=0.71)$. One hundred and nine $(56.5 \%)$ subjects were already using hormonal treatment at the first appointment, and there were significantly more MtFs than FtMs already using hormone therapy (MtF: 87, 69.6\%; FtM: $22,32.3 \% ; \mathrm{OR}=4.87, \mathrm{p}<0.01)$

Analysis of age at first perception of GI indicated that this occurred in 109 subjects (56.5\%) during childhood, 37 (19.2\%) during adolescence, and $14(7.2 \%)$ during adulthood; 33 subjects $(17.1 \%)$ could not specify their ages at the first perception of GI (Figure 2). Among MtFs, 63 (50.4\%) reported the first perception of GI during childhood, $29(23.2 \%)$ during adolescence, and 7 (5.6\%) during adulthood; 26 subjects $(20,8 \%)$ could not specify their ages at the first perception of GI. Among FtMs, 46 (67.6\%) 
reported the first perception of GI during childhood, 8 (11.8\%) during adolescence, and $7(10.3 \%)$ during adulthood; 7 subjects $(10.3 \%)$ could not specify their ages at the first perception of GI. A Chi square test indicated that a higher percentage of FtMs than MtFs first perceived GI during childhood $(\mathrm{OR}=2.05, \mathrm{p}=0.02)$.

\section{Discussion}

The present study aimed to identify the age when individuals first perceived GI, and to compare the sociodemographic characteristics of MtFs and FtMs in a sample of Brazilian study subjects with GI. Our study sample consisted of 125 (64.8\%) MtFs and $68(35.2 \%)$ FtMs, a ratio of about 3:2. Most previous studies of transgender subjects reported much higher percentages of MtFs (Pauly, 1968; Landén, Walinder, \& Lundström, 1996; Arcelus, Bouman, \& Van den Noortgate, 2015). The lower percentage of MtFs in our sample may be a reflection of the type of people referred to our service. Most referrals are from gynecologists of the Ribeirão Preto regional health district, who usually receive female patients. Another possible reason for our lower percentage of MtFs may be that MtFs can perform self-medication with hormones, because they do not need prescriptions to access hormonal treatment (Ministério da Saúde, 2015). In contrast, legal access to testosterone by FtMs requires a prescription, so FtMs may be more likely to attend our service for initiation of hormone therapy.

Many patients with GI arrive at our service while already on hormone medications and as adults, possibly due to a lack health care and difficulties in accessing the health system because of preconceptions by health care professionals and a fear of discrimination. Previous studies demonstrated that transgender individuals have difficulties in accessing health care systems (Bento, 2006; Bento, 2012). This is in direct conflict with the principles of equity, integrality, and universality of health care in Brazil, 
and contrary to decree 2836 of December 1, 2011, which established full access to health care for the LGBT population in an effort to eliminate discrimination and institutional prejudice (Ministério da Saúde, 2013).

Two-thirds of our sample population reported being employees, but the prevalence of prostitution was low (4.2\%). According to the Associação Nacional de Travestis e Transexuais (ANTRA), 90\% of this population resorts to prostitution as a source of income at some time during their lives (Cunha, 2017). A 2015 cross-sectional study that used a semi-structured interview at this same outpatient clinic found that 8 of 44 people (18\%) with GI reported working as prostitutes (Lerri, et al., 2017). Interestingly, the current study of 193 people still found only 8 records of patients wording in prostitution, suggesting that there have been no new reports of prostitution since 2015 (Lerri, et al., 2017) evaluated the same service and found that half of all patients receiving treatment had incomes that were between the minimum wage and 3times above the minimum wage, and $25 \%$ had incomes that were more than 3-times above the minimum wage. These data suggest that this population is well integrated into the labor market, although it should be noted that these data were not obtained objectively and some of this reported income may have been from prostitution even though this is not shown in the records.

Almost $20 \%$ of our study subjects were students. The literature suggests that schools can be hostile environments for people with GI, and there are several reports of prejudice, violence, and abuse in schools, factors that restrict access to education and lead to greater marginalization of individuals with GI (Ziotti \& Santos, 2018). Sex education programs are essential for improving the inclusion of individuals with GI in educational environments (Silva \& Megid Neto, 2006). In addition, changing the social environment, such as choosing a name and wearing clothes in accord with the self-identified gender, 
and provision of appropriate toilets, can reduce violence and discrimination (Guss, Shumer, \& Katz-Wise, 2015). In our sample, FtMs were more common in schools than MtFs, possibly indicating greater acceptance of FtMs in the school environment. FtMs also appear to have a higher quality of life than $\mathrm{MtFs}$, in schools and elsewhere, although both groups have lower quality of life than the cisgender population.

In our study, all subjects who reported working in prostitution and all who were positive for HIV and other STIs were MtFs. The prevalence of HIV in our MtFs was 17.6\%. In Brazil, the prevalence of HIV infection is 5-times higher among transsexuals than in the general population (Institute of Medicine, 2011), and reaches 25\% in some regions (Costa, et al., 2015 ). A recent study in Brazil found that the prevalence of HIV positivity among men who have sex with men is $18.4 \%$ (Kerr, et al., 2018), similar to the prevalence in our sample of MtFs (17.6\%).

There are limited data in the literature on smoking, drinking, and drug use in transsexual populations, although most studies include gender minority assessments (Hoffman, Delahanty, Johnson, \& Zhao, 2018). A 2013 cross-sectional study in the United States found greater tobacco use by transgender than cisgender people (Buchting, et al., 2017). This was the first national prevalence study on this issue in the United States. In our sample, one-third of MtFs and one-quarter of FtMs reported use of tobacco. According to 2013 data from the Instituto Brasileiro de Geografia e Estatística (IBGE), the prevalence of tobacco use is $14.7 \%$ in Brazil (IBGE, 2014). Smoking is a major risk factor for thrombosis, and should especially be avoided by MtFs taking estrogen due to the increased cardiovascular risk (Hembree, 2017).

According to the WHO, alcohol abuse increases the risk for major noncommunicable chronic diseases, as well as accidents and violence (IBGE, 2014). The prevalence of alcohol use in our sample was $18.1 \%$, with no statistical difference between 
MtFs and FtMs. According to 2013 data from the IBGE, the percentage of the Brazilians who consume alcohol one or more times a week is $24.0 \%(36.3 \%$ in men and $13 \%$ in women; 33). Alcohol consumption by our subjects overall was lower than the national prevalence, although 35\% more $\mathrm{MtFs}$ reported drinking alcohol than cisgender women (19.1\% vs. 13\%). A 2017 Brazilian study showed that alcohol abuse is common among transvestites. In particular, Kerr-Corrêa et al. (2017) evaluated 304 transvestites and found that three-quarters of them consumed alcohol in the last year and had scores more than 8 on the WHO Alcohol Use Problems Identification Test (AUDIT). They noted that alcohol consumption was associated with increased risk of unprotected sex, drug use, and HIV infection (Kerr-Corrêa, et al., 2017).

The percentage of our study subjects who used illicit substances (marijuana, cocaine, and ecstasy) was $11.9 \%$ overall (MtF: $13.6 \%$ FtM: $11.7 \%$ ). However, these data may be underestimates because they are self-reported. According to Day et al. (2017), the prevalence of psychoactive substance use is 2.5- to 4-times higher among transgender than cisgender individuals. Younger people are more likely to use these substances, possibly due to their increased emotional and social vulnerability, although using psychoactive substances could actually increase their anxiety, depression, and risk for other psychiatric disorders (Day, Fish, Perez-Brumer, Hatzenbuehler, \& Russell, 2017). There are limited data on psychoactive substance use in Brazil, but a study of eighthgrade adolescents in Ribeirão Preto showed that $6.8 \%$ of students used marijuana, $2.7 \%$ used cocaine, $1.6 \%$ used hallucinogens, and $0.3 \%$ used an opiate (Muza, et al., 1997). Another household survey conducted in 107 cities in Brazil examined individuals aged 12 to 65 years-old and found that the $6.9 \%$ used marijuana, $2.3 \%$ used cocaine, and $5.8 \%$ used volatile solvents. The data of our sample was based on a simple "yes" or "no" response; we have no data on the frequency or amount of psychoactive substances that 
were used. As reported by Day et al., the higher prevalence of psychoactive drug use by individuals with DI may be the result of social marginalization and the increased risk of psychological problems in this population (Day, Fish, Perez-Brumer, Hatzenbuehler, \& Russell, 2017)

A notable finding in our study is the low prevalence of self-reported anxiety and depression. A European study reported that the prevalence of depression in a GI population assessed between 2007 and 2010 was 38\% (Heylens, et al., 2014). In contrast, based on evaluation of medical records, there were medical diagnoses of depression in 9.8\% of our GI individuals (MtF: 8.8\%, FtM: 11.8\%). A 2015 cross-sectional study in this same setting that used semi-structured interviews found that more than $80 \%$ of this population suffered from depression and anxiety (Lerri, et al., 2017). The low prevalence of depression and anxiety in the medical records of our subjects suggests that medical caregivers may not have performed adequate psychological and psychiatric assessments of these individuals. It is worth remembering that the rate of suicide ideation and attempted suicide, which derive from poor mental health, are up to 20-times higher in those with GI than in the general population (Blosnich, et al., 2013). Thus, it is important to better train medical teams to consider complaints related to depression and anxiety, and to evaluate affective relationships and the need for emotional support (Lerri, et al., 2017).

A total of $56.5 \%$ of our subjects used hormones prior to the first appointment, and this use was especially high among MtFs (69.6\%). Self-medication without the supervision of qualified professionals could cause major health problems. The prevalence of pathologies associated with increased cardiovascular risk in our population was $10.3 \%$. Individuals with GI tend to engage in self-medication with hormones. In particular, MtFs often use oral estrogen and high-doses of hormonal contraceptives, and FtMs often use 
illicit testosterone (Ministério da Saúde, 2015). Hormone treatment is crucial to achieving the desired gender characteristics (Hembree, 2017). In particular, the use of estrogens by MtFs increases breast size, fat deposition in the hip region, and reduces testosterone levels; the use of testosterone by FtMs increases muscle mass, clitoris size, and secondary sexual characteristics (body hair and voice) (Hembree, 2017). However, these hormones should only be administered by skilled health care providers. Indiscriminate use of hormones can lead to serious side effects, such as thromboembolic disease, breast and endometrial cancer, erythrocytosis, coronary and cerebrovascular disease, liver dysfunction, and transient infertility (Hembree, 2017).

The age when most individuals in our sample reported the first perception of GI was childhood, followed by adolescence. Less than $10 \%$ reported this event during adulthood. Data about the age of the first perception of GI are scarce, but a 1988 study suggested that feelings of GI occur early in life (Blanchard, 1988). Our findings, obtained through the evaluation of gynecologists in a sexual health service, corroborate these previous findings, and may therefore help to develop specific protocols for providing more integrated health care to individuals with GI. Previous prospective studies showed that only 2 to $27 \%$ of children who manifest GI maintain this diagnosis during adolescence and adulthood (Wallien \& Cohen-Kettenis, 2008). Most of these children become cisgender, homosexual, or bisexual, but those with stronger expression of GI during childhood have a greater probability of having GI during adulthood (Wallien \& Cohen-Kettensis, 2008). Thus, when a child reaches adolescence and GI persists, there is a high probability that GI will remain during adulthood. A follow-up study of 70 adolescents diagnosed with GI who underwent hormone suppression therapy showed that all remained the same gender in adulthood, thus suggesting that identity consolidation occurs prior to this phase (de Vries, Steensma, Doreleijers, \& \& Cohen-Kettenis, 2010). 
In the present study, we have no records of the behaviors of our subjects during childhood that could be used to suggest the presence of GI at that time. Many times, there are reports that adults with GI had a fondness for clothing and accoutrements typically associated with the other gender, and sometimes there are records about a child's feelings about the genital organs during early childhood. The Gender Identity Disorder in Childhood Scale (GIDICS), an 11-item questionnaire that evaluates the desire to belong to the opposite sex and to wear clothes, play, and behave like the opposite sex during childhood, has not yet been validated for the Portuguese language. Use of this questionnaire may help to elucidate these issues. Research suggests that although GI develops early in life, it only begins to cause discomfort during adolescence and adulthood (Smith, van Goozen, Kuiper, \& \& Cohen-Kettenis, 2005).

\section{Study Limitations}

All of our data are from medical record review, based on the reports of individuals with GI and their caregivers. There is therefore a possibility of detection and/or diagnostic bias, because certain sensitive information may not have been reported by the study subjects.

\section{Conclusion}

We conclude that most individuals with GI first perceive the onset of this condition during childhood, and that a higher percentage of FtMs than MtFs first perceive GI during childhood. Further studies are needed to identify the factors that affect the age at which an individual first perceives GI. There are higher prevalences of HIV, STIs, and prostitution in MtFs, and FtMs appear to be better integrated in school environments. 
Relative to FtMs, MtFs have higher prevalences of smoking, alcohol use, recreational drug use, and self-medication with hormones.

\section{Compliance with Ethical Standards:}

This research project was submitted for review to the Research Ethics Committee of the University of São Paulo at Ribeirão Preto Medical School. The practical activities of this project were guided by the ethical norms of Resolution 466/2012 of the National Health Council on Research with Human Beings. Because this study was based on a review of medical records, waiving of the consent form was requested and authorized. The author's don't have any conflicts of interests. 


\section{References}

ARCELUS, J., BOUMAN, W. P., \& VAN DEN NOORTGATE, W. E. (2015) Systematic review and meta-analysis of prevalence studies in transsexualism. European Psychiatry, 30(6), 807-15

BAKKER, J. et al. (2006) Alpha-fetoprotein protects the developing female mouse brain from masculinization and defeminization by estrogens. Nat Neurosci, Feb;9(2), p. 220-6.

BENTO, B. (2006). A reinvenção do corpo: sexualidade e gênero na experiência transexual. Rio de Janeiro: Garamond.

BENTO, B. (2012) Sexualidade e experiências trans: do hospital à alcova. Cien Saude Colet , v. 17, n. 10, p. 2655-2664.

BLANCHARD, R. (1988). Nonhomosexual gender dysphoria. Journal of Sex Research, v. 24, p. 188-193,

BLOSNICH, J. et al. (2013). Prevalence of gender identity disorder and suicide risk among transgender veterans utilizing veterans health administration care. Am J Public Health, v. 103(10), n. Oct, p. e27-32.

BONIFACIO, H. J.; ROSENTHAL, S. M. (2015). Gender Variance and Dysphoria in Children and Adolescents. Pediatr Clin North Am., v. 62, n. 4, p. 1001-16,

BUCHTING, F. O. et al. (2017). Transgender Use of Cigarettes, Cigars, and ECigarettes. American Journal of Preventive Medicine, v. 53, n. 1, p. e1-e7. 
COSTA, A. B. et al. (2015). Population-based HIV prevalence and associated factors in male-to-female transsexuals from Southern Brazil. Arch Sex Behav, v. 44(20, n. Feb, p. 521-4.

CUNHA, T. (2017). Transexuais são excluídos do mercado de trabalho. Correio Brasiliense,

DAY, J. et al. (2017). Transgender Youth Substance Use Disparities: Results From a Population-Based Sample. J Adolesc Health. , n. Dec;61(6), p. 729-735

DE CUYPERE, G.; T’SJOEN, G.; BEERTEN, R. E. A. (2005). Sexual and physical health after sex reassignment surgery. Archives of Sexual Behavior, v. v. 34, p. i. 6, 2005. 34(06):679-690.

DE VRIES, A. L. C. et al. (2010). Puberty suppression in adolescents with gender identity disorder: A prospective follow-up study. The Journal of Sexual Medicine, n. Advance online publication.

ECKER, J.; , A. T.; SYLVESTRE, J. (2017). A Review of the Literature on LGBTQ Adults Who Experience Homelessness. J Homosex, n. Dec 5, p. 1-27.

FERNÁNDEZ, R., GUILLAMÓN, A., CORTÉS-CORTÉS, J., GÓMEZ-GIL, E., JÁCOME, A., ESTEVA, I., PÁSARO, E. (2018). Molecular basis of Gender Dysphoria: androgen andestrogen receptor interaction. Psychoneuroendocrinology, 98, 161-167.

GUSS, C.; SHUMER, D.; KATZ-WISE, S. L. (2015). Transgender and Gender Nonconforming Adolescent Care: Psychosocial and Medical Considerations. Curr Opin Pediatr, v. 26(4), n. Aug, p. 421-426 
HEMBREE, E. A. (2017). Endocrine Treatment of Gender-Dysphoric/GenderIncongruent Persons: An Endocrine Society Clinical Practice Guideline. Journal of Clinical Endocrinology \& Metabolism, p. v. 102, i. 11, 102(11):3869-3903.

HENNINGSSON, S., WESTBERG, L., NILSSON, S., LUNDSTROM, B., EKSELIUS, L., BODLUND, O., LANDEN, M. (2005). Sex steroid-related genes and male-to-female transsexualism. Psychoneuroendocrinology, 30, 657-664.

HEYLENS, G. et al. (2014). Psychiatric characteristics in transsexual individuals: multicentre study in four European countries. Br J Psychiatry, v. Feb, n. 204 (2), p. 151156.

HOFFMAN, L. et al. (2018). Sexual and gender minority cigarette smoking disparities: An analysis of 2016 Behavioral Risk Factor Surveillance System data. Prev Med, v. 113, n. Aug, p. 109-115.

IBGE. (2014). Pesquisa Nacional de Saúde 2013. Rio de Janeiro.

ICD-11 (2018). International Classification of Diseases 11th Revision.

INSTITUTE OF MEDICINE. (2011). The Health of Lesbian, Gay, Bisexual, and Transgender People: Building a Foundation for Better Understanding. Washington, DC.

KERR, L. et al. (2018). HIV prevalence among men who have sex with men in Brazil: results of the 2nd national survey using respondent-driven sampling. Medicine (Baltimore), v. 97, n. 1S Suppl 1, p. S9-S15.

KERR-CORRÊA, F. et al. (2017). Hazardous alcohol use among transwomen in a Brazilian city. Cad Saude Publica, v. Apr 3; p. 33(3). 
KUDWA, A., MICHOPOULOS, V., GATEWOOD, J., \& RISSMAN, E. (2006) Roles of Estrogen receptors alpha and beta in differentiation of mouse sexual behavior. Neuroscience, 138, 921-928

LANDÉN, M.; WALINDER, B.; LUNDSTRÖM, B. (1996). Prevalence, incidence and sex ratio of transsexualism in Sweden. Acta Psychiatrica Scandinavica, p. 93:2613.

LERRI, M. R. et al. (2017). Clinical Characteristics in a Sample of Transsexual People. Revista Brasileira De Ginecologia E Obstetrícia, v. v. 39, p. 39:373-440.,

MCCARTHY, M. (2008) Estradiol and the Developing Brain. Physiological Reviews, p. 91-134

MINISTÉRIO DA SAÚDE (2013). Portaria do Ministério da Saúde no 2.803 de 19 novembro de 2013 - Redefine e amplia o Processo Transexualizador no Sistema Único de Saúde (SUS).

MINISTÉRIO DA SAÚDE. (2015). Transexualidade e Travestilidade na Saúde. Brasilia - DF: Editora MS.

MUZA et al. (1997). The consumption of psychoactive substances by adolescents in schools in an urban area of Southeastern region of Brazil. I - Prevalence by sex, age and kind of substance. Journal of Public Health, v. 31, n. 1, p. 21-29

PAULY, I. B. (1968). The current status of the change of sex operation. Jornal of Nervous and Mental Desease, p. 147(5):460-71.

RAZNAHAN, A., LEE, Y., STIDD, R., LONG, R., GREENSTEIN, D., CLASEN, L., \& ADDINGTON, A. (2010) Longitudinally mapping the influence of sex and 
androgen signaling on the dynamics of human cortical maturation in adolescence. ProcNatl Acad Sci U S A., 107, 16988-16993.

ROSENTHAL, S. M. (2012) Approach to the patient: transgender youth: endocrine considerations. J Clin Endocrinol Metab, 99(12), 4379-4389.

SILVA, R. C. P.; MEGID NETO, J. (2006). Background of teachers and educators for approach to sexual education at schools: what research works show. Ciência $\mathbf{E}$ Educação, v. 12, n. 2, p. 185-197

SMITH, Y. L. S. et al. (2005). Sex reassignment: outcomes and predictors of treatment for adolescent and adult transsexuals. Psychological Medicine, v. 35, p. 89-99, CONSELHO FEDERAL DE MEDICINA (2020). Resolução no. 2265, de 20 de Setembro de 2019. Diário Oficial da União.

WALLIEN, M. S. C.; COHEN-KETTENIS, P. (2008). Psychossexual outcome of gender-dysphoric children. Journal of the American Academy of Child \& Adolescent Psychiatry, p. v. 47, i. 12, 47:1413-23.

WHO. (1986). Young People's Health - a Challenge for Society Report of a WHO Study Group on Young People and "Health for All by the Year 2000". Genebra.

ZIOTTI, M. C.; SANTOS, M. A. (2018). Capítulo 7: o contexto do aluno transexual. In: Qualidade e Políticas Públicas na Educação 2. Ponta Grossa (PR): Atena Editora, p. $73-80$. 


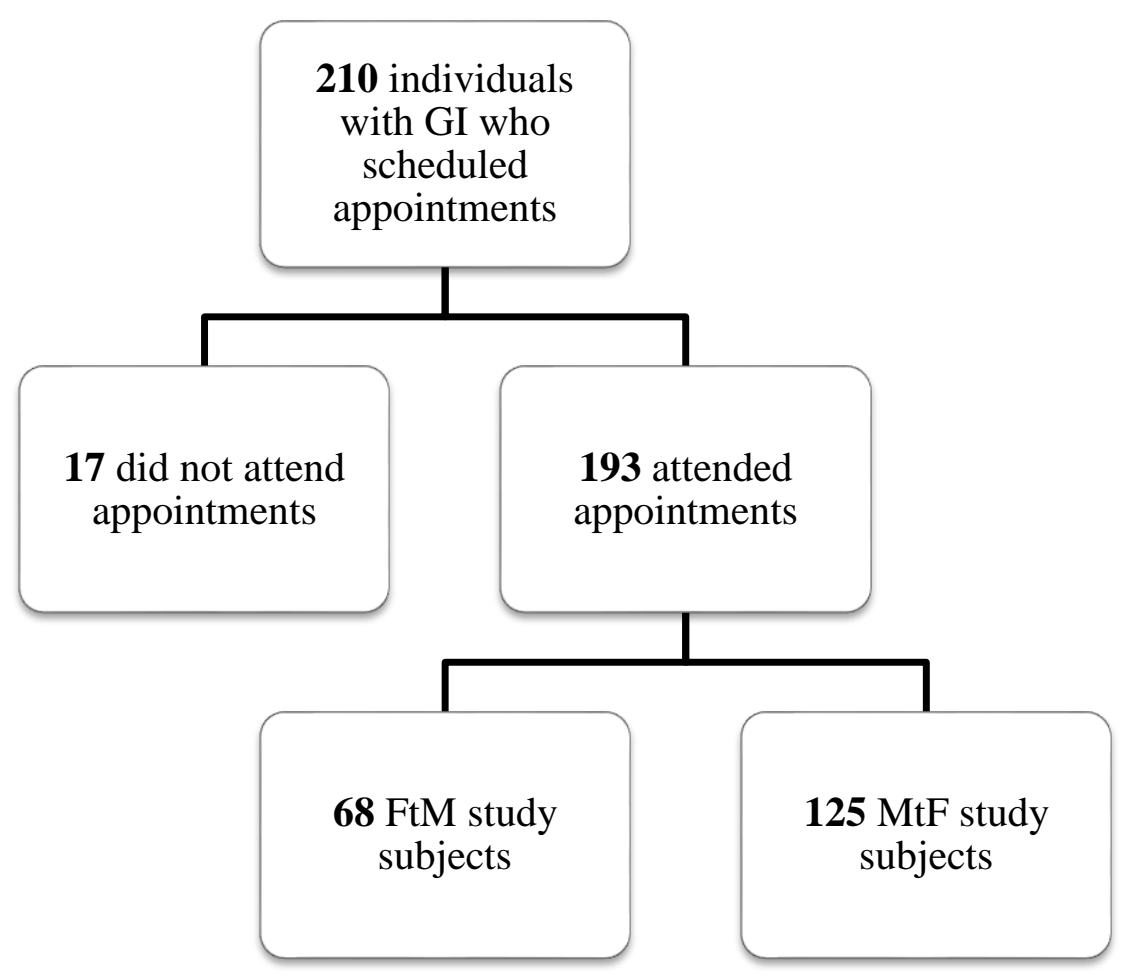

Figure 1. Disposition of individuals with GI who scheduled appointments with AING from January 2010 to July 2018. 


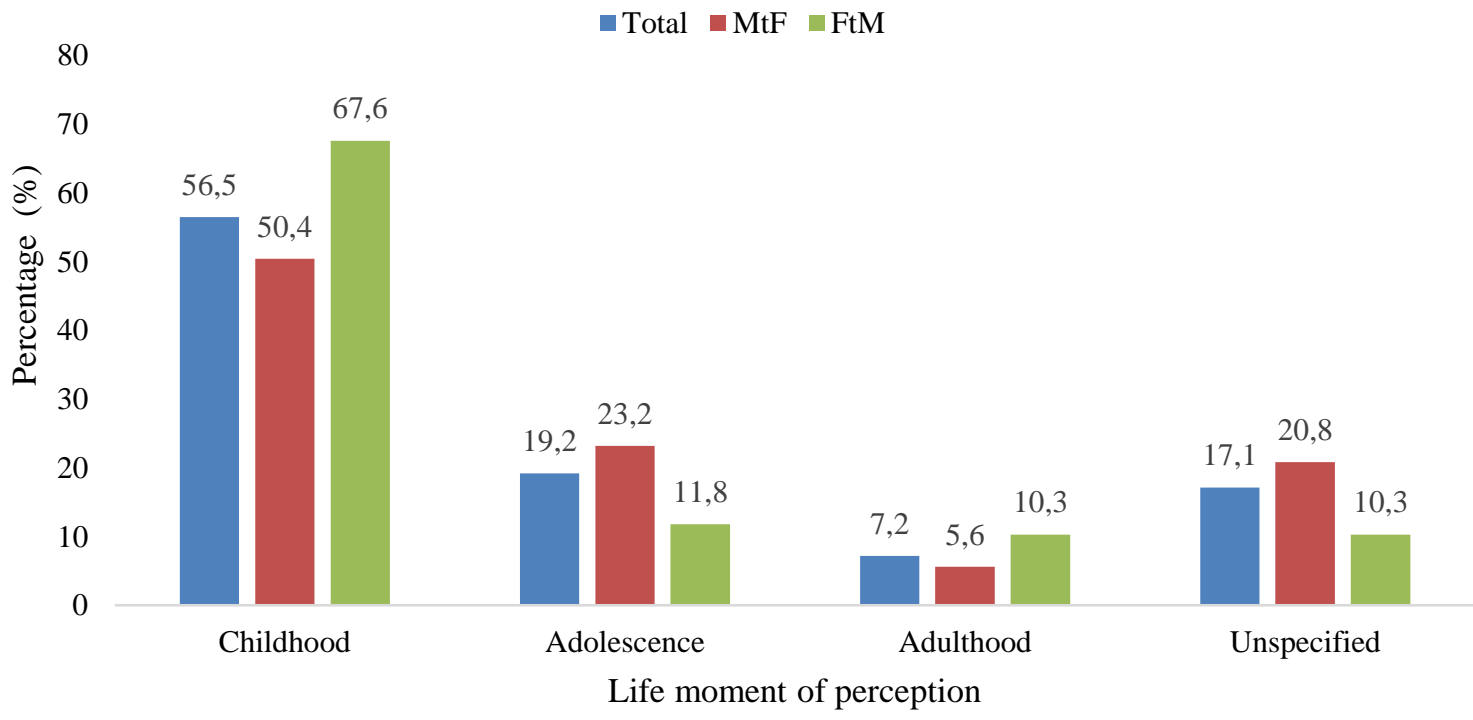

Figure 2. Age when study subjects first perceived GI (childhood: younger than 10 years-old, adolescence: age 10 to 19 years-old, adulthood: more than 19 years-old). 
Table 1. Sociodemographic and clinical characteristics of study subjects.

\begin{tabular}{|c|c|c|c|c|}
\hline & Total, N (\%) & MtF, N (\%) & FtM, N (\%) & $\mathbf{p}$ \\
\hline Variable & $193(100)$ & $125(64.8)$ & $68(35.2)$ & \\
\hline \multicolumn{5}{|l|}{ Age (years) } \\
\hline$<18$ & $17(8.8)$ & $11(8.8)$ & $6(8.8)$ & \\
\hline 18 to 29 & $129(66.8)$ & $75(60.0)$ & $54(79.4)$ & \\
\hline 30 to 50 & $43(22.3)$ & $36(28.8)$ & $7(10.3)$ & \\
\hline$>\mathbf{5 0}$ & $4(2.1)$ & $3(2.4)$ & $1(1.5)$ & \\
\hline \multicolumn{5}{|l|}{ Employment status } \\
\hline Employee & $128(66.3)$ & $88(70.4)$ & $40(58.8)$ & 0.10 \\
\hline Prostitution & $8(4.1)$ & $8(6.4)$ & $\mathbf{0}(\mathbf{0})$ & 0.03 \\
\hline Student & $36(18.7)$ & $18(14.4)$ & $18(26.5)$ & 0.03 \\
\hline Unemployed & $29(15.0)$ & $19(15.2)$ & $10(14.7)$ & 0.92 \\
\hline
\end{tabular}




\begin{tabular}{|c|c|c|c|c|}
\hline \multicolumn{5}{|l|}{ Clinical risk factors } \\
\hline Cardiovascular factor & $20(10.3)$ & $15(12.0)$ & $5(7.4)$ & 0.31 \\
\hline Anxiety/depression & $19(9.8)$ & $11(8.8)$ & $8(11.8)$ & 0.51 \\
\hline STI & $26(13.5)$ & $26(20.8)$ & $\mathbf{0}(\mathbf{0})$ & $<0.01$ \\
\hline HIV & $22(11.4)$ & $22(17.6)$ & $\mathbf{0}(\mathbf{0})$ & $<0.01$ \\
\hline Smoking & $50(35.9)$ & $27(21.6)$ & $23(33.8)$ & 0.06 \\
\hline Alcohol use & $35(18.1)$ & $22(17.6)$ & $13(19.1)$ & 0.79 \\
\hline Drug use & $23(11.9)$ & $17(13.6)$ & $8(11.7)$ & 0.71 \\
\hline Prior hormone use & $109(56.5)$ & $87(69.6 \%)$ & $22(32.3)$ & $<0.01$ \\
\hline
\end{tabular}




\section{Abbreviations}

AING Gender Incongruence Clinic

ANTRA Associação Nacional de Travestis e Transexuais

AUDIT Alcohol Use Disorders Identification Test

DSM-V Diagnostic and Statistical Manual of Mental Disorders, Fifth Edition

FtM Female-to-Male

GI Gender incongruence

GIDICS Gender Identity Disorder in Childhood Scale

HIV Human immunodeficiency virus

IBGE Instituto Brasileiro de Geografia e Estatística

ICD-11 International Classification of Diseases 11th Revision

N Sample size

MtF Male-to-Female

WHO World Health Organization

STI Sexually transmitted infection

USP Universidade de São Paulo 